\title{
The lived experience: Stories from those who have encountered catastrophic loss from flood
}

\author{
Margaret R. Rateau \\ West Virginia University
}

Follow this and additional works at: https://researchrepository.wvu.edu/etd

\section{Recommended Citation}

Rateau, Margaret R., "The lived experience: Stories from those who have encountered catastrophic loss from flood" (2011). Graduate Theses, Dissertations, and Problem Reports. 3481.

https://researchrepository.wvu.edu/etd/3481

This Dissertation is protected by copyright and/or related rights. It has been brought to you by the The Research Repository @ WVU with permission from the rights-holder(s). You are free to use this Dissertation in any way that is permitted by the copyright and related rights legislation that applies to your use. For other uses you must obtain permission from the rights-holder(s) directly, unless additional rights are indicated by a Creative Commons license in the record and/ or on the work itself. This Dissertation has been accepted for inclusion in WVU Graduate Theses, Dissertations, and Problem Reports collection by an authorized administrator of The Research Repository @ WVU.

For more information, please contact researchrepository@mail.wvu.edu. 
The lived experience: Stories from those who have encountered catastrophic loss from flood

\author{
Margaret R. Rateau \\ Dissertation submitted to the School of Nursing \\ at West Virginia University \\ in partial fulfillment of the requirements \\ for the degree of \\ Doctor of Philosophy \\ in \\ Nursing \\ Committee members: \\ Mary Jane Smith, Ph.D., RN, Committee Chairperson \\ Joy Buck, Ph.D., RN \\ Roger Carpenter, Ph.D., RN \\ Alvita Nathaniel, Ph.D., RN \\ Renee Willow, B.S. \\ Morgantown, West Virginia \\ 2011
}

Key words: natural disaster, flood, lived experience, catastrophic loss

Copyright 2011 Margaret R. Rateau 


\section{ABSTRACT \\ The lived experience: Stories from those who have experienced catastrophic loss from flood Margaret R. Rateau}

Natural disasters including flood affect thousands of people all over the world each year. As a direct result, millions of dollars in widespread damage occur in the regions directly impacted by such disasters. Analyzing stories from those who have suffered catastrophic loss from flood may offer a means to better understand what is important to the survivor from their perspective and may assist in the recovery process. The purpose of this research was to examine the lived experience of those who have experienced catastrophic loss from flood. The importance of this research and its impact on nursing knowledge development, research, and practice are discussed. A review of the literature, substantiation of the theoretical underpinnings for this study, and data collection and analyses are explained. Fourteen themes were identified that represent the structure of meaning of the lived experience of a flood event where catastrophic loss had occurred. 


\section{Dedication}

This dissertation is dedicated to my husband Robert, son, Marc, and daughter Chelsea. For without their love and support, this work could not have been possible. Always know how much I love you all. I dedicate this work to my family members especially my parents, dear friends, and co-workers who were there to "cheer me on" when I needed it the most. Finally, I dedicate this work to those who have suffered losses as a result of natural disaster. May these stories help heal those who have experienced similar circumstances and provide comfort in knowing that their stories are important. 


\section{Acknowledgements}

I would like to acknowledge those individuals who have served as positive influences and sources of strength and encouragement throughout this educational journey. First, I would like to thank God, for without his blessings-I would have not been afforded the amazing opportunity to complete this work. I would like to thank my dissertation committee members Dr. Mary Jane Smith, Dr. Joy Buck, Dr. Roger Carpenter, Dr. Alvita Nathaniel and Ms. Renee Willow for their unending support, guidance and expertise throughout this project. A special thanks to Dr. Mary Jane Smith, dissertation committee chairperson. She has served as a mentor in so many ways, and her constant support and guidance will not be forgotten. She will always hold a special place in my heart, and I only hope that this "butterfly" will be able to spread her wings to help others as Dr. Smith has done for me.

I would like to thank my family, friends, and co-workers for their constant support and words of encouragement throughout this endeavor. A special thanks to my classmates Tony, Joyce, Terri, Amy, Jennifer, and Tina for their friendship and support. We all share a very important bond with one another and I will never forget how special you all are to me. A special thanks to my dear friend Tina-this journey would have not been the same without you! Lastly, thanks to those who shared their stories of loss and healing. Your willingness to share your experiences will hopefully serve as catalysts for the healing of others who have suffered similar losses. 


\section{TABLE OF CONTENTS}

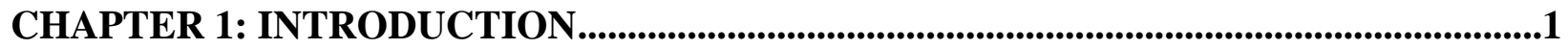

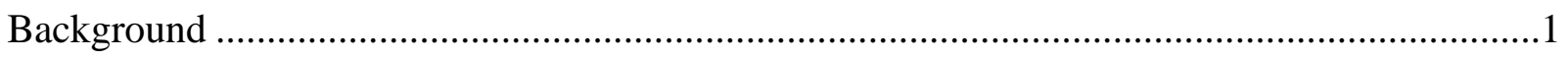

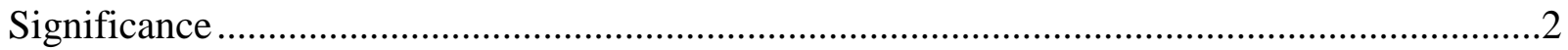

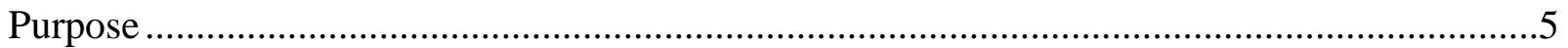

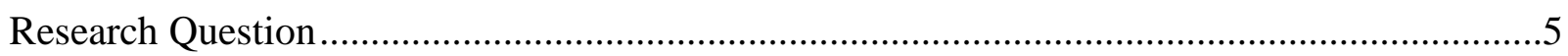

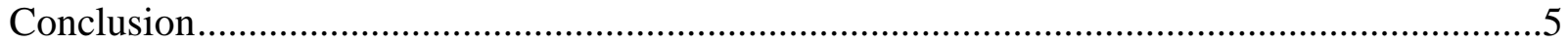

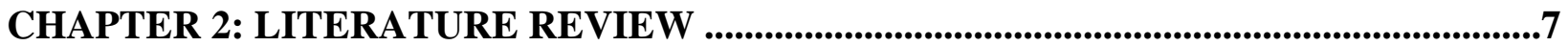

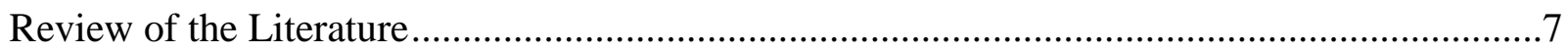

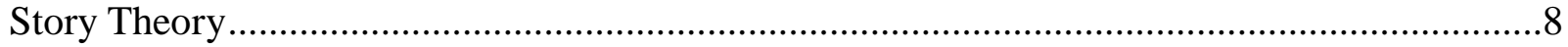

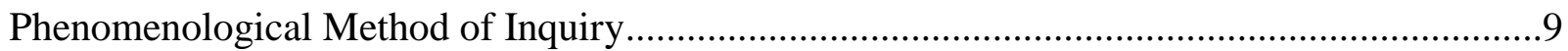

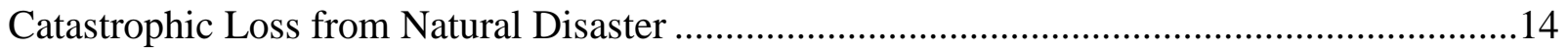

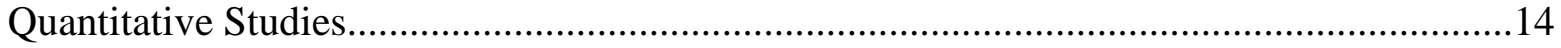

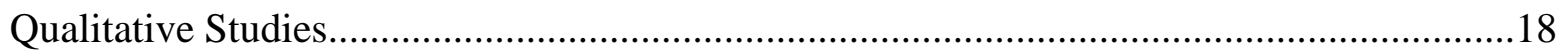

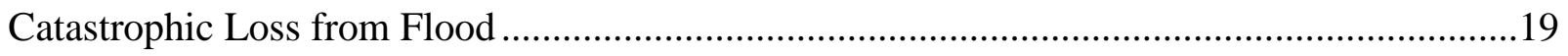

Quantitative Studies............................................................................................. 19

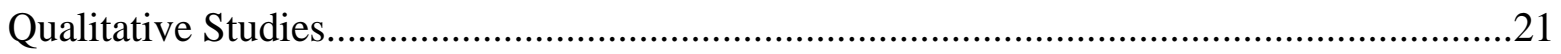

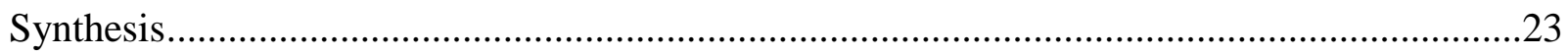

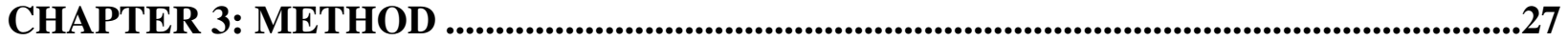

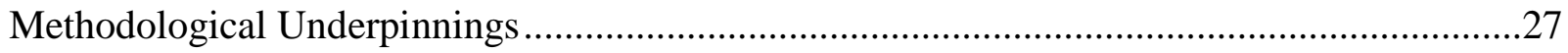

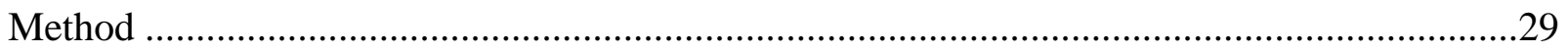

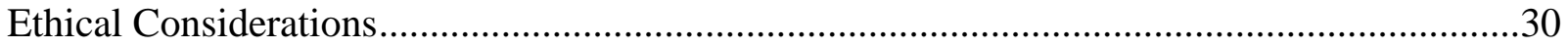

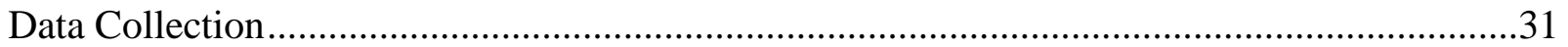

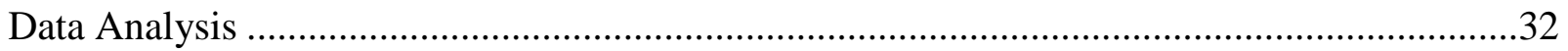

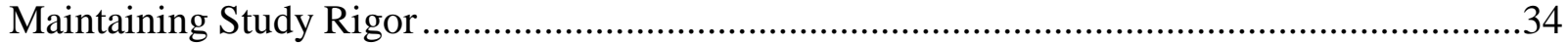

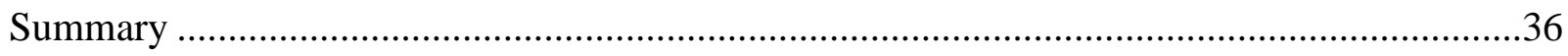

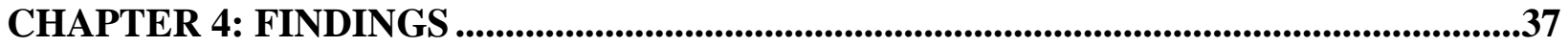

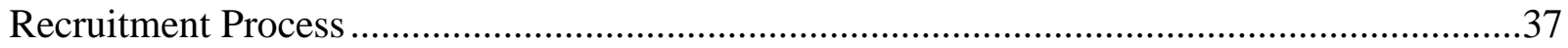

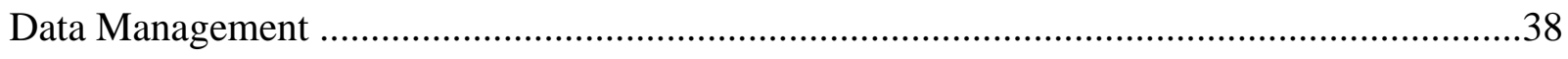




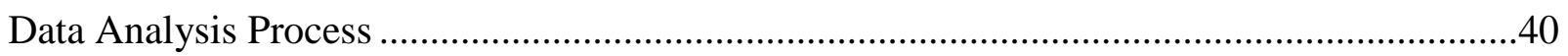

Getting a Sense of the Whole by Dwelling with Each Story ...........................................40

Discriminating Meaning Units to Organize the Beginning, Middle, and End of Each Story 40

Transforming Participant's Language into the Language of the Researcher .......................41

Identifying Consistent Statements of the Transformed Meaning Units ..............................41

Synthesizing Themes in the Structure of Meaning of the Lived Experience ........................42

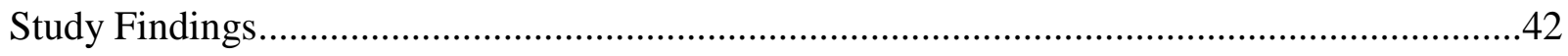

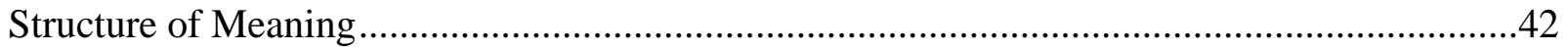

Beginning as the usual day despite heavy rainfall.....................................................44

Increasing recognition of the rising flood waters as communicated by warnings via family,

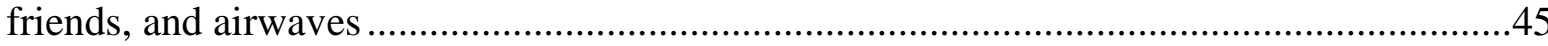

Growing apprehension when faced with the rising flood waters and the likelihood of damage to come.....

Shifting to concentrate on what needs to be done to secure possessions and the safety of pets in the midst of the rising waters

Watching the power and destruction of the rising flood waters in agonizing disbelief .49

Retreating in haste from the danger of the rising flood waters to the safe reprieve of higher ground and relative's homes......

Seeing yet not believing the chaos and expansive devastation when returning to their home53 Coming to know the breadth of destruction and substantial ruination of belongings and

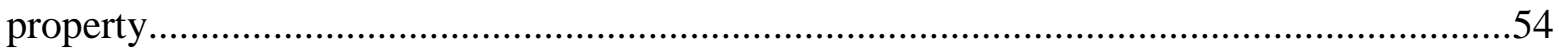

Contemplating the overwhelming task to restructure life and home to what once was .........55

Overwhelming heartfelt gratitude for the assistance of others to reestablish home and property destroyed by the flood waters ....................................................................56

Taking on the effort to rebuild with energy and commitment........................................58

Making deliberate choices about future life decisions in light of the flood experience.........59

Living an always present uneasiness when there is heavy rainfall .................................61

Reflecting on a changed life perspective that surfaces in day to day living........................62

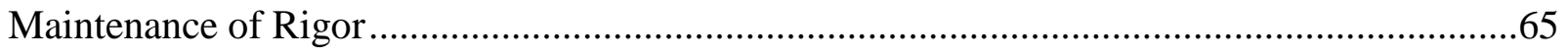

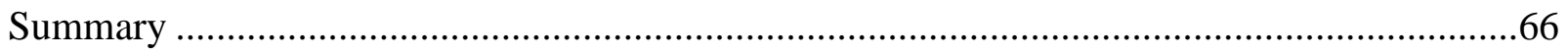




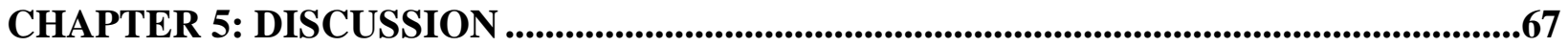

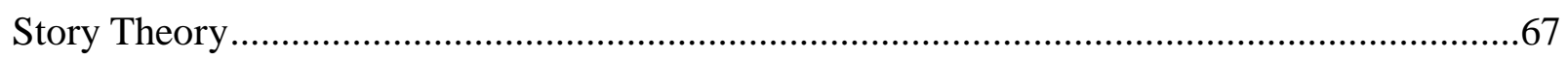

Intentional Dialogue ……………………………………................................................68

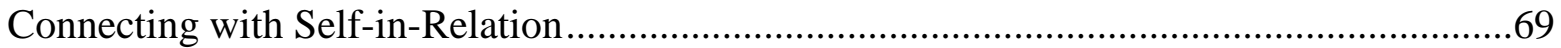

Facing the devastation ...............................................................................................69

Embracing the rebuilding ...........................................................................................71

Developing an inner strength ......................................................................................72

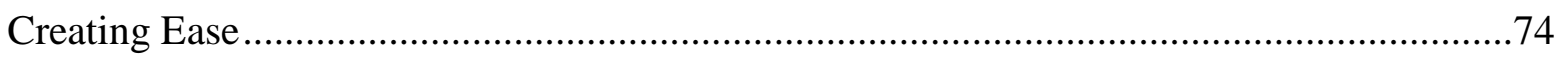

Transformation ..............................................................................................................

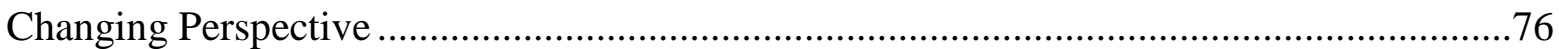

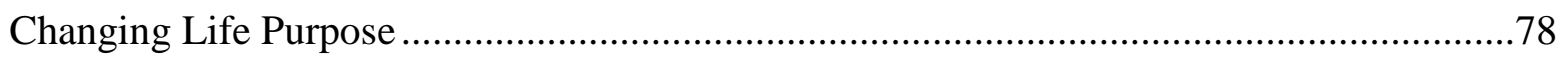

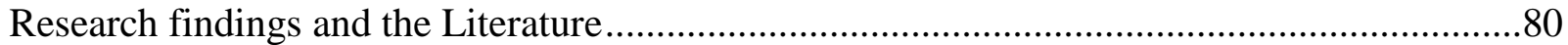

Implications for Nursing Knowledge Development, Research, and Practice .............................82

Implications for Nursing Knowledge Development.............................................................82

Implications for Nursing Research .........................................................................................83

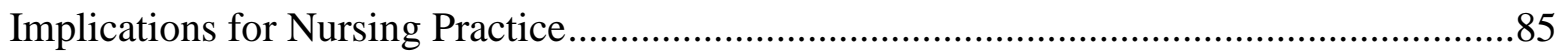

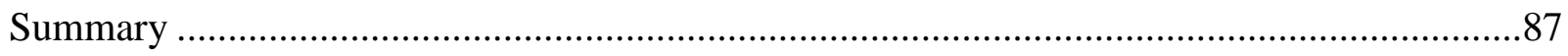

REFERENCES.....................................................................................................................................88

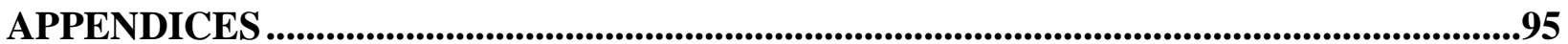




\section{Chapter 1-Introduction}

This chapter discusses the background, significance, and purpose of the proposed study entitled "The lived experience: Stories from those who have encountered catastrophic loss from flood.” This chapter provides a foundation for the importance of the research and the potential influence on nursing science, practice, and health policy. In addition, through this research, a clearer understanding of the impact of catastrophic loss from the survivor's perspective was acquired.

\section{Background}

Thousands of Americans experience catastrophic loss due to natural disaster annually. Many survivors require physical, emotional, and financial support which may continue for years (Popp, 2006). This situation is no different for people affected by flood from significant rain events or from coastal storms including hurricanes. According to the NOAA's National Weather Service (NWS) Office of Climate, Water and Weather Services (2008) extreme weather accounted for 3.2 billion dollars in property damages, with flash and river flooding producing 3.4 million dollars in damage in 2008.

The emotional consequences of catastrophic loss can occur through the loss of personal identity and delayed psychological recovery for those affected by such disasters (Rateau, 2009). These consequences were evident following the Hurricane Katrina disaster, which produced unprecedented and devastating floods in August, 2005. In promoting a positive psychological recovery for flood survivors and in gathering stories from the perspective of those who have encountered such an event, a clearer understanding of the impact following catastrophic loss was 
gained. This understanding is particularly important when planning and implementing appropriate long-term emotional and physical support to natural disaster survivors.

In the quest to gain insight from the survivor's perspective, a qualitative method using story theory (Liehr \& Smith, 2007) for data collection and subsequent interpretation was planned. This middle-range theory fits appropriately within this realm of inquiry given a focus of this study is on the meaning of stories that facilitate a caring presence between the nurse and the person sharing the story (Liehr \& Smith, 2008). There are qualities of the phenomenological approach of inquiry that complement story theory (Smith \& Liehr, 1999). This complement is achieved through the recognition of the full essence of the story's beginning, middle, and end which lead to unfolding of story moments, identification of themes, and in the synthesis of stories shared both individually and collectively (Smith \& Liehr, 1999).

\section{Significance}

Newman, Sime, \& Perry (1991), propose that a discipline is distinguished by a specific domain of inquiry, and in nursing it is the study of caring in the human health experience. In striving to explore the meaning of caring in the human health experience, gathering stories to understand the lived experience adds to the body of knowledge in nursing by elaborating on the human health experiences associated with catastrophic loss. This study contributes to the discipline through a deeper understanding of the survivor's human health experience following a flood event.

It is important to understand an individual's health experiences following catastrophic loss from natural disaster. Negative mental health effects including depression and anxiety often 
increase following such disasters (V. Adams, Hattum, \& English, 2009; Kessler, 2006; Kim, Plumb, Gredig, Rankin, \& Taylor, 2008). However, the duration in which these effects linger and the designation of interventions designed to provide long-term support for survivors of catastrophic loss remains unclear. Further research is needed to examine the disaster survivor's recovery over an extended period of time (Benight \& McFarlane, 2007). This study contributes to this need by exploring the meaning of stories from survivors that experienced catastrophic loss from massive flooding in September, 2004.

Stories illuminating the survivor’s perspective may be integral in developing nursing knowledge and in providing clarity for understanding recovery from catastrophic loss. In particular, qualitative methods for exploring the phenomenon are needed to better understand the meaning of such loss from the perspectives of people who have experienced it. The findings of this research may contribute to improved nursing practices which are created to meet the needs of those who suffer from catastrophic loss in the future.

Evidence suggests that finding meaning associated with traumatic events, including disaster survival, may be important to long-term recovery and further research is needed (Benight \& McFarlane, 2007; Exline, Smythe, Gregory, Hockemeyer, \& Tulloch, 2005; Ibanez, Buck, Khatchikian, \& Norris, 2004). Further theoretical sophistication is needed in future research to address essential issues relative to survivor recovery following natural disaster.

A challenge to understanding the effects of natural disaster lies in describing the nature and meaning of the experience from the individual's perspective (Benight \& McFarlane, 2007). Based on story theory, this perspective is necessary when planning and delivering appropriate 
health care to people encountering catastrophic loss following natural disaster. Further, little research exists that is guided by nursing theory on the lived experience of catastrophic loss from flood. This represents a gap in the nursing body of knowledge, since most research has not considered this area of inquiry for exploring the meaning of catastrophic loss following natural disaster.

Phenomenological research has recently been identified as a valid approach for examining nursing as a science of caring, contributing knowledge that holds practical relevance to nursing (Flood, 2010). The phenomenological approach to inquiry provides a means to discover the essences of an experience and offers a way in which human phenomena of persons can be studied and ultimately understood (Flood, 2010). Research using this kind of qualitative approach from the survivor's perspective remains less prevalent, particularly over extended periods of time, increasing the knowledge gap further.

The qualitative method of investigation for this research may hold substantive influence in understanding the deep meaning of living through catastrophic loss, which is essential in survivor recovery and may hold important implications for nursing practice. Findings may provide nurses with a broader foundation to better meet the needs of flood survivors who have experienced catastrophic loss. Since nurses form a significant and integral proportion of the healthcare team following disaster, it is crucial that they possess the knowledge and skills needed to promote health during the recovery process following disaster (Hughes, Grigg, Fritsch, \& Calder, 2007). 


\section{Purpose}

The purpose of this research was to explore the structure of meaning in stories of those who have lived through the experience of a flood event where catastrophic loss has occurred. According to the Oxford American Dictionary (2002), catastrophe is defined as "a great and unusual sudden disaster; an event producing a subversion of the order of things” (p. 117). Although prior research studies have investigated physical and psychological needs associated with natural disaster recovery (R. Adams \& Boscarino, 2005; Benight \& Harper, 2002; Exline, et al., 2005; Raholm, Arman, \& Rehnsfeldt, 2008; Yoon, 2009), only few specific to survivor recovery from flood exists in the literature. Providing the opportunity for the flood survivor to tell and share their story, embraces connectivity between that person and nurse, encouraging a meaning-making process of the experience (Smith \& Liehr, 1999).

\section{Research Question}

The question posed in this study was: What is the structure of meaning in the experience of living through a flood situation where there is catastrophic loss?

\section{Conclusion}

This research holds important implications in the areas of nursing knowledge development, research, and practice. Practice applications may be enhanced to better meet the needs of survivors affected by natural disaster. The meaning of the experience of catastrophic loss illuminated through the story of flood survivors contributes to a better understanding of what matters most to the survivor, thus holding essential information for clinicians to enhance patientcentered care. Findings from this research provide important contributions to the body of nursing 
knowledge, nursing research, and nursing practice through emphasis on the flood survivor's perspective potentially creating both different and effective care modalities that assist in the recovery process. 


\section{Chapter 2-Literature Review}

To better understand the meaning of catastrophic loss from the survivor's perspective, a comprehensive review of the literature was conducted. This review served to investigate current theoretical and empirical literature that offers foundational support for the proposed research study. This chapter provides an overview of the literature. The review will be presented in the following order: first, story theory, secondly, the phenomenological method, thirdly, quantitative and qualitative studies on catastrophic loss from natural disaster, and fourth, quantitative and qualitative studies on catastrophic loss from flood. Lastly, a synthesis of the literature will be presented.

\section{Review of Literature}

In conducting the review of literature, the databases of Academic Search Premier, CINAHL with full text, Psych Articles, Health Source Academic/Nursing Edition, Medline Plus with full text, Sociology Index, and Psychology and Behavioral Health Collection were used. Throughout the last three to four years, repeated searches have been conducted approximately three times a year to obtain the most current literature available. Key words and phrases including trauma, disaster, natural disaster, property loss, home loss, phenomenology, lived experience, life purpose, life meaning, meaning, story, story theory and flood were consistently used during multiple searches. The phrase policy making was included in the search performed in February 2010. Combinations of these key words and phrases produced approximately one hundred publications collectively within all databases. Reference list selections provided an additional thirty resources related to disaster effects on survivors. The twelve resources selected 
for detailed discussion within this literature review were chosen based on significant relevance associated with the proposed study. Previous studies involving natural disaster especially flood, suggest a connection between property, material, and/or home loss with survivor recovery and literature substantiating the chosen method of inquiry are the focus of this review. The most relevant literature related to the study is discussed under the topics of Phenomenological Method of Inquiry, Catastrophic Loss from Natural Disaster, and Catastrophic Loss from Flood.

\section{Story Theory}

According to Smith \& Liehr (2008), the three interrelated concepts of intentional dialogue, connecting with self-in-relation, and creating ease compose story theory. This middle range nursing theory fits well with the purpose of this study as it relates to the gathering of stories of people who have experienced catastrophic loss from flood. When applied to the research setting, the nurse researcher's focus is on the participant and the story being told while completely engaging in the moment, thus creating intentional dialogue.

Intentional dialogue and the two associated processes of true presence and querying emergence, occur as the nurse stays with the person telling the story in order to uncover the real meaning of the story being shared. Being in the true presence during these processes is critical for the story to emerge with a distinct beginning, middle, and end. As the story unfolds, the direction may need clarifying, so the nurse may gain insight to what is being told from the person’s perspective.

Connecting with self-in-relation encompasses the two processes of personal history and reflective awareness (Smith \& Liehr, 2008). Personal history is revealed when the individual 
telling the story ponders about the past, present, and future hopes and dreams that relate to the health challenge or focus of the story. Reflective awareness or the connection between bodily experiences, feelings and thoughts and self is important for the person telling the story to recognize. As the nurse guides this process, the person telling the story is able to acknowledge what is and is not known, thereby creating new meaning to emerge within the story plot. Story plot is described as the unfolding qualities of the story being told that describe the health challenge (Liehr \& Smith, 2007). Story plot links present, past, and future in a synthesis of the unfolding story.

Creating ease arises as the story plot comes together to create a unified and meaningful whole. The two elements of creating ease include remembering disjointed story moments and flow in the midst of anchoring (Smith \& Liehr, 2008). Remembering disjointed story moments involves linking events in time to recognize the whole story. Flow in the midst of anchoring is portrayed by finding meaning in the story as patterns are recognized. Continued resolution of the health challenge is manifested through the emerging feelings of harmony and in discovering the meaning of the story.

\section{Phenomenological Method of Inquiry}

A new philosophy initially developed by Edmund Husserl (1900-1970) known as "phenomenology" became a significant influence in the $20^{\text {th }}$ century. This philosophy focused on consciousness, the nature of human beings in relation to their worlds (Giorgi, 2005). Husserl believed that consciousness separated phenomenology from other areas of philosophy, serving as a medium between human beings and the world (Giorgi, 2005). Several years later, one of 
Husserl's students, Heidegger (1927) developed his own approach to phenomenology, rooted by strong personal interest in the method and a difference in philosophy associated with Husserlian Transcendental Phenomenology practices (McConnell-Henry, Chapman, \& Francis, 2009). It is critical that the assumptions exclusive to the phenomenological method of inquiry be explicit when considering how the method is appropriate for exploration of the research question posed in this study.

Assumptions of the method. There are several important assumptions of the phenomenological method to consider when conducting qualitative research. One assumption is that the method thematizes the phenomenon of consciousness, or the totality of the lived experience that belongs to that individual person (Giorgi, 1997). Further, there is a specific meaning to the term "phenomenon" through the presence of that which appears precisely as it is given or experienced, for that person. This is manifested in how the experience presents itself to one’s awareness through consciousness (Giorgi, 1997). A second assumption of the phenomenological method is that of intentionality. Intentionality is viewed as an essential feature of consciousness, and is an act of consciousness that is directed toward an object that always transcends that act (Giorgi, 1997). This means that transcendence, often accompanied by consciousness, serves as a channel for openness with our self, others, and the world and in the establishment of new types of relationships into the world (Giorgi, 2005).

According to Giorgi (1997), the phenomenological method of inquiry involves three interrelated phases: reduction, description, and the search for essence. The initial step of reduction involves bracketing previous knowledge regarding the phenomenon of interest so that the phenomenon may be explored with a fresh perspective and described precisely as it is 
experienced or given. The practice of bracketing may be used to establish trustworthiness in the data collection and analyses processes in qualitative research including some phenomenological methodologies. One approach to bracketing is to put aside preconceived notions regarding the phenomenon being examined, thereby eliminating researcher bias as much as possible (Ahern, 1999; Connelly, 2010; Hamill \& Sinclair, 2010).

In keeping with this approach to bracketing, the researcher published an article entitled “A Story of Transformation Following Catastrophic Loss.” in 2010 (Rateau, 2010). The purpose of the publication was to share the researcher's autobiographical story of catastrophic loss following a house explosion and fire. The article presented the transpersonal perspective of transformation and research and practice applications for persons who may experience such losses. The preparing, writing, and publication of this autobiography offered the researcher the opportunity to bracket preconceived notions regarding catastrophic loss from disaster.

A second approach to bracketing was espoused by Heidegger. He developed a different phenomenological philosophy following a hermeneutic or interpretive nature, which supports the notion that the separation of the observer from the world is not possible to avoid bias. This idea fuses the social world of the participant with the observer to collectively create reality (Bradbury-Jones, Irvine, \& Sambrook, 2010; Hamill \& Sinclair, 2010). A person cannot bracket personal perspectives as these views are dimensions of being human. These perspectives create the lens for the phenomenon of study and are made explicit by the researcher; in that meaning comes from the research-phenomena interchange (Ahern, 1999; Bradbury-Jones, et al., 2010; Hamill \& Sinclair, 2010; McConnell-Henry, et al., 2009). The lens for this study includes the human health experience as viewed through story theory and phenomenological inquiry. 
Description refers to language used to convey to others objects of consciousness, in which one is present in the exact manner in which it is offered. It is the narrative used by an individual to express intentional objectives of consciousness of any given situation precisely as it appears in that situation (Giorgi, 1997). This process assists in gaining insight and in communicating the perspectives of others' specific experiences in context of the everyday or natural attitude (Giorgi, 1997).

Lastly, the search for essence of the phenomenon is an important outcome from analysis of phenomenological inquiry, and is described as the constant identity that limits the variations the phenomenon can undergo, and is critical to the meaning of conscious lived experience (Giorgi, 1997). Simply put, it is the presence of continual distinctive qualities that remain in a phenomenon that reduce the alterations the phenomenon may undertake (Giorgi, 1997).These qualities are recognized through the process of free imaginative variation (Giorgi, 1997, 1985; Kleiman, 2004). Using this process, essential attributes of the phenomenon are identified by probing and examining the meaning units derived from the data to ascertain which attributes may identify the structure of meaning or essence of the phenomenon being studied (Giorgi, 1997; Kleiman, 2004).

Structure of meaning. A goal of phenomenological research is to acquire a deeper understanding of the nature of meaning in everyday experiences. Meaning is a complex term which occurs on many levels. Lived meaning is a way a person experiences the world as real in a given situation (van Manen, 1997). Giorgi (2005) describes meaning in phenomenological inquiry as a search for essences that constitute the meaning of the lived experience. He ties meaning to the attitude of everyday life as lived in a situation. 
Phenomenology is the retrospective exploration of the lived experience (van Manen, 1997). This methodology differs from most others, in that it seeks to discover the essential structures of life experience without categorizing or conceptualizing them. The researcher uncovers significant essences of the lived experience being examined through orientation of the phenomenon being explored, maintaining dedication to the exploration of the lived experience, and continual reflection to find meaning within that experience (van Manen, 1997). In uncovering essences of the lived experiences, the internal structure of the meaning of the experience is revealed. Interpretation of patterns or themes for their uniqueness and reoccurrence in the phenomenon being examined may be disseminated through thoughtful reflection and finally in written language.

Incorporation of story theory and phenomenological approaches. The incorporation of important principles from the phenomenological approach of inquiry with story theory offers a method for acquisition and analysis of stories collected from those who have experienced catastrophic loss from flood. The use of the research participant's story serves as a significant link between the phenomenological method and story theory and is critical in the meaning making process of a significant life event (Smith \& Liehr, 1999). Through dialogue, the researcher encourages and supports the participant to describe the lived experience being explored.

Further, the manner in which data are collected and analyzed is comparable between the phenomenological method of inquiry adapted by Giorgi (Giorgi, 1997) and story theory. These comparisons are evidenced through intentional query to gather the story or descriptive dialogue from the participant's perspective gaining a sense of the whole story, identifying meaning units 
or themes, and synthesizing the story on both an individual and collective basis (Smith \& Liehr, 1999). For these reasons, this method is suitable for this study which explores the meaning of stories shared by those who have experienced catastrophic loss from flood.

\section{Catastrophic Loss from Natural Disaster}

Quantitative studies. A descriptive retrospective study from India investigated the impact of a supercyclone on survivors' locus of control, anxiety, and posttraumatic stress disorder or PTSD (Suar, Mandal, \& Khuntia, 2002). Structured interviews were conducted three months after the cyclone hit, with an affected $(n=65)$ group and an unaffected ( $n=65)$ group. Selected items from the Internal-External Locus of Control Scale, Beck’s Depression Inventory, and DSM IV criteria for PTSD were used to measure behaviors associated with conditions being investigated. Following multiple regression, results indicated that those in the affected group who lost family members and property experienced more anxiety, depression, and PTSD than the unaffected group. Loss was measured through questions comparing family, agricultural, livestock, and home existence before and after the cyclone. External locus of control, a behavior characterized by the belief that life events are attributed to external factors such as God, fate, or chance evaluated by the Internal-External Locus of Control Scale, and anxiety using the STAI Form X-2 were measured. Study results indicated that higher amounts of loss significantly increased both external locus of control and anxiety levels in disaster survivors (Suar, et al., 2002).

A descriptive correlational study was conducted to investigate the relationship between quality of life and psychiatric impairment in residents of a Taiwanese community affected by an 
earthquake disaster in 1999 (Chou, et al., 2004). Interviews conducted using the Disaster-Related Psychological Screening Test (DRPST), a tool specifically designed and validated to assess psychiatric impairment associated with natural catastrophe and Short Form Health Survey were given to community residents $(n=4223)$ four to six months after the disaster. Following chi square, analysis of variance, and multiple regression analyses, interviewees were categorized into four psychiatric impairment groups based on DRPST scores. These categories included: healthy ( $n=952)$, mild-moderate $(n=1823)$, moderate-severe $(n=1126)$, and severe $(n=322)$ psychiatric impairment groups.

The four categories of participants were compared for relevant factors including age, gender, marital status, and psychiatric impairment scores to assess overall quality of life following the disaster. Following analysis, participants identified as psychologically impaired tended to be female, older in age, less educated, single and/or divorced, and had experienced major familial financial loss due to house destruction immediately following the earthquake. Male respondents were categorized in the psychologically healthy group more frequently than in all other psychologically impaired groups. Reasons for this gender difference are not given by the researchers however it may be that women in this study were more vulnerable following the earthquake. Further, there was a marked negative correlation between severity of psychiatric impairment and quality of life on both physical and mental dimensions as measured by the Short Form Questionnaire (Chou, et al., 2004).

Another descriptive correlational study in Iceland investigated the psychological consequences of two earthquakes which occurred in June, 2000 with an affected sample group $(n=52)$ and unaffected control group $(n=29)$ being examined three months following the 
earthquake. These numbers demonstrate response rates following random sampling of 150 participants for each group (Bodvarsdottir \& Elklit, 2004). The influence of coping style, gender, social support, and world view on the development of PTSD symptoms was investigated. The main finding is that after a moderate earthquake, a portion of the exposed population developed PTSD symptoms. Overall, 24\% of the participants in the affected group fulfilled the criteria for the diagnosis of PTSD, while none were found in the control group. Additionally, of the 12 participants who met the PTSD criteria, 75\% of those were displaced from their homes for more than 48 hours, and 83\% continued to live in homes that sustained major damage (Bodvarsdottir \& Elklit, 2004). Further, emotional coping style, ability to express thoughts and feelings, and earthquake-related anxiety predicted $81 \%$ of HTQ (Harvard Trauma Questionnaire) variance in both groups, with property damage being significantly related to total HTQ scores (Bodvarsdottir \& Elklit, 2004).

A cross-sectional descriptive study examining the presence of and risks for PTSD was conducted in Nicaraguan residents affected by Hurricane Mitch six months after the disaster in October, 1998 (Caldera, Palma, Penayo, \& Kullgren, 2001). The study included participants visiting four primary health care centers $(\mathrm{n}=496)$ located in rural communities affected by the hurricane in northern Nicaragua. A structured questionnaire encompassing demographic variables, including age, sex, and educational level, type and degree of trauma exposure including family/property loss, presence of PTSD symptoms, and help-seeking behavior resultant from the disaster was used. Results indicate 38.5\% ( $\mathrm{n}=191)$ of participants reported the death or injury of a close relative, with 34.0\% (n=169) having homes partially/completely destroyed. 
Following multiple and logistic regression, PTSD symptoms were significantly associated with death of a relative, home destruction, female sex, previous mental health problems and illiteracy.

Collectively, $5.8 \%$ of all participants $(n=29)$ were identified as meeting PTSD baseline criteria, with 7.7\% $(\mathrm{n}=13)$ of those who had their home destroyed experiencing PTSD compared to $4.9 \%$ of other participants (Caldera, et al., 2001). Those participants $(n=29)$ originally identified as meeting the PTSD criteria were included in follow-up assessments one year after the hurricane. Seventy-nine percent $(n=23)$ were included in the follow-up which following same statistical analyses, revealed 52.2\% $(n=12)$ continuing to meet the criteria necessary for the diagnosis of PTSD, with no other significant differences among variables in those who had PTSD and those who did not one-year following the disaster (Caldera, et al., 2001).

A comparison study examining psychosocial functioning in children and individual adjustment in family groups following a wildfire disaster in Northern California was conducted six weeks after its occurrence in 2000 (Jones, Ribbe, Cunningham, Weddle, \& Langley, 2002). Although the target subjects were individuals and families that sustained significant loss to home and property from the fire, a post-hoc measure of resource loss was constructed comparing high loss (HL) and low loss (LL) groups for the presence of psychological symptoms. In this study, resource loss was defined as destruction of property, deprivation of time, insult to health, and/or loss of internal or external resources resultant from the fire. Following analyses using independent/dependent t-tests, and one-way ANOVA, those respondents in the HL group reported slightly higher PTSD symptoms (5.0 vs. 4.2) and statistically significantly higher scores on the Impact of Events Scale and Resource Loss Index. Further, parents reported 2.1 more PTSD symptoms than their children (Jones, et al., 2002). 
A large U.S. retrospective cross-sectional national study investigated the prevalence, characteristics, and presence of long-term psychological symptoms following exposure to a variety of natural disasters (Briere \& Elliott, 2000). The random sample ( $\mathrm{n}=1442)$ obtained for this study was representative of the general population of the United States, thereby allowing for results obtained to be generalized. The Traumatic Events Survey (TES), which evaluated the presence of a variety of childhood and adult traumas including natural disaster exposure and the Trauma Symptom Inventory (TSI) which measured posttraumatic stress and other psychological indicators following traumatic events were mailed to participants. Three follow-up reminders were provided to potential respondents one month apart.

Of all potential participants, 935 (64.8\%) returned surveys with 22\% reporting exposure to natural disaster and of that, 57\% reporting loss of possessions (Briere \& Elliott, 2000). Further, reports of previous disaster exposure (average length 13 years) in those affected were associated with significantly higher scores on 6 of 10 symptom scales contained on the Traumatic Events Survey and Trauma Symptom Inventory. In addition, disaster characteristics including property loss were better predictors of the presence of symptoms, than actual type of natural disaster experienced. (Briere \& Elliott, 2000).

Qualitative studies. A qualitative study conducted in two Mexican and one American city explored various coping strategies used by Mexican survivors following disaster (Ibanez, et al., 2004). Survivors were interviewed in Guadalajara $(n=10)$ five years following a neighborhood sewer explosion, in Puerto Angel three months after Hurricane Paulina (n= 11) and Homestead, FL $(n=6)$ five years following Hurricane Andrew. Following data collection and coding, four themes of seeking support, seeking meaning, problem solving, and avoidance 
emerged (Ibanez, et al., 2004). Seeking support involved actively seeking emotional and informational support from others, expressing emotion with others, providing support to others, and sharing humor with others.

Activities supporting the theme of seeking meaning were identified through making sense of the event using religious or spiritual guidance to feel better, discovering what is important in life, changing stressors in a positive manner, and believing that something was learned from the experience. Problem solving included activities directed toward seeking solutions to the problem, and negotiating, bargaining, and compromising to get something positive from the situation. Finally the theme avoidance was characterized by efforts centered on refusal to dwell on the problem through distraction of oneself, exhibiting stoic attitudes toward life, and use of emotional distancing, rationalization, and substance abuse to cope with the aftermath of the disaster. Further, seeking support $(n=25)$ was the priority coping strategy in all three groups. The other coping strategies including seeking meaning $(n=18)$ varied in frequency and order of priority among groups and were influenced by disaster type, resource availability, and stage of recovery (Ibanez, et al., 2004).

\section{Catastrophic Loss from Flood}

Quantitative findings. A follow-up retrospective study examining the role of psychosocial resource loss was conducted following significant flooding in the Midwestern United States in 1993 (Smith \& Freedy, 2000). The sample used for this study (n=131) was part of a larger sample originally used in1995 and was selected through the return of second questionnaires sent to all participants. The Flood Exposure Scale, which measured displacement 
from home and property damage, and personal injury, along with psychosocial resource losses which identified personal and social resource losses, psychological distress, and physical symptoms were measured via questionnaire to participants from local flood-affected communities six weeks and six months post disaster. Following chi square, correlation coefficient and path analysis, psychosocial resource loss was related to both psychological distress and physical symptoms with psychosocial resource loss mediating effects of flood exposure, psychological distress, and physical symptoms six months post-flood (Smith \& Freedy, 2000). Further, psychosocial resource losses most frequently identified by participants included: losses of routine, sense of control, sense of optimism, accomplishing goals, and time spent with loved ones (Smith \& Freedy, 2000).

A case study was conducted investigating how internal community assets influenced the rebuilding process of a small North Carolina community devastated by flood five years earlier in 1999 (Yoon, 2009). Data collected via questionnaire ( $\mathrm{n}=127)$ included participant assessments of elected leadership, community cohesion, mental health state of depression in flood survivors, perceived financial recovery to pre-flood level and current emotional status. (Yoon, 2009). These characteristics were measured through Community Cohesion Scale (CSS), Center for Epidemiologic Studies Depression Scale (CES-D), and a four-item leadership scale developed by the author. Data were also collected through semi-structured interviews with key informants $(\mathrm{n}=7)$ including town and emergency management leaders, religious personnel, and long-time resident and civic leader, as well as through review of community and governmental agency policies and procedures regarding emergency management. 
Study findings revealed a significant relationship between assessed depression, elected officials’ ability to mobilize needed resources, and financial recovery in rebuilding the community (Yoon, 2009). Qualitative data uncovered a common theme of recognizing the symbolic meaning of being the first town chartered by African Americans in the country and was considered the most precious internal asset in the rebuilding process. Other themes included the unique need of being identified as an aged town which motivated survivors to rebuild, and the expressed positive interpretation of the disaster as a blessing and opportunity to become better than before the flood (Yoon, 2009).

Qualitative studies. A longitudinal hermeneutic phenomenological study was conducted in Sweden exploring the immediate lived experiences of victims and relatives of the 2004 tsunami tragedy in Southeast Asia (Raholm, et al., 2008). Individual and group interviews (n=19) were conducted 21 months after the catastrophe and included Swedish persons or their significant others within support groups that experienced the tsunami disaster. Data were analyzed using Ricoeur's theory of interpretation and its signature steps of naive reading, structural analyses, and comprehensive understanding. Three themes, alternatively described as acts from a drama were identified. These themes included experiencing the very core of existence, a changed understanding of life, and the power of communion (Raholm, et al., 2008). The first theme of experiencing the very core of existence was reflected in descriptions involving chaos, unanswered questions, the struggle to survive, life and death, and detachment. The second theme, a changed understanding of life, was illustrated by keeping hope despite the feelings of powerlessness, being humbled by consequences beyond control, and feelings of extreme loss while continuing to comfort loved ones, and strangers. Finally, the power of 
communion was demonstrated through the coming together with others to share stories and in the strong sacred or spiritual dimension embraced by participants allowing for a deeper understanding of life meaning and purpose. Further, participants found suffering together with other family members or finding meaning through community added a valuable dimension to their own lives (Raholm, et al., 2008).

Another phenomenological study examined how residents of two coastal Louisiana communities framed environmental change, specifically participant thoughts regarding sense of place and the continued progression of wetland loss in the area where they resided (Burley, Jenkins, Laska, \& Davis, 2007). Forty seven in-depth interviews were conducted with residents of the Grand Isle and Terrebonne communities exploring the meaning of place attachment and continual loss of coastal land. Analysis of residential narratives found constant and heightened sense of place attachment through the elements of fragility and uniqueness relative to the communities in which they lived (Burley, et al., 2007).

Within the context of the study, the element of uniqueness refers to the expectation that coastal land loss or erosion will likely continue within the community and is viewed as a matter of urgency. The theme fragility closely related to uniqueness, involved changes in the social, cultural, and environmental aspects of the communities in which the participants resided caused by the ongoing land loss in the region. In addition, residents expressed feelings of vulnerability related to uncertainty of land restoration in the area and a lack of control in the decision-making process for future land restoration plans (Burley, et al., 2007). 
A longitudinal study conducted in two English communities examined the extent and type of physical and psychological health impacts associated with a flood event that took place over the Easter holiday in 1998 (Tapsell \& Tunstall, 2008). Focus groups were held with participants who experienced property damage from floodwaters. The focus groups were conducted with the same participants during three separate times over a $4 \frac{1}{2} 2$ year period. Findings included that many participants felt differently about their homes and the region in which they lived following the flood even after refurbishment had taken place. Furthermore, residents experienced feelings of isolation and loss of a sense of security regarding the local area and private homes in which they resided. The resident's choice to remain in hazardous environments immediately following the flood was interpreted as place attachment. The authors infer that even small localized flood events may facilitate disruption in the lives of survivors and have a negative impact on long-term physical and mental health well-being (Tapsell \& Tunstall, 2008).

\section{Synthesis}

\section{Characteristics of the Literature Review}

The preceding literature review served as groundwork for further investigation of catastrophic loss following natural disaster, specifically from flood. The twelve research studies demonstrate a diverse representation of work regarding the psychological effects and factors associated with material/property losses in those who have survived natural disaster. Further, several studies addressing personal perspectives and meaning in regard to physical locale or place of residence are represented within this review. The following synthesis reiterates the 
important work completed in the area of natural disaster research, including flood and the influence property and/or home loss may have on the recovery process.

Study designs. Research studies discussed in this literature review include seven quantitative, three qualitative, and two multi-method designs. While a large proportion of the studies within this review are quantitative in nature, qualitative and mixed-method research are represented in the literature, especially in the area of flood recovery and perception pertaining to sense of place. Due to the foci, a majority of these studies are descriptive and retrospective in nature and serve to provide clarity regarding the correlation between natural disaster recovery and demographic and/or other influencing factors. The factors discussed vary however, all assist in adding to the body of knowledge in psychology and health-related disciplines.

Location of studies. A large proportion of the research found in regard to this review included studies conducted in a variety of regions around the world. This is evidenced through studies being completed in Asia, India, Europe, Iceland, Central America, Mexico, and the United States. The disasters studied vary and are reflective of the type of disaster that affected the location where the research was conducted. The authors of these studies did not address cultural differences in relation to the disaster experiences.

Disaster types studied. The disaster types researched within the literature review included: hurricanes, floods, earthquakes, tsunami, wildfire, and supercyclone which took place between the years of 1993 and 2004. With the exception of a sewer explosion all are considered natural disasters that produced widespread damage to the areas affected. In addition, personal perceptions regarding the location in which survivors' resided and the meaning of place are 
illuminated in two studies, which assist in recognizing the importance between material and/or property losses and survivor recovery following natural disaster.

\section{Major Findings in the Literature}

There are several consistent findings noted within the literature regardless of the type of disaster being investigated, study design, or location where the research was completed. Further, there are additional findings that are exclusive to a specific study that are worth noting. All of these findings contribute to an enhanced understanding of the recovery from a natural disaster resulting in a broadened knowledge base. These findings will be discussed in association with the method of study.

Quantitative findings. An important finding that is consistently noted within the literature involves the presence of and factors associated with psychological or PTSD symptoms in survivors of natural disaster. Findings reveal generally significant higher levels of negative psychological symptoms or PTSD in survivors of natural disaster where loss of property and/or home or injury to self or a loved one was involved (Bodvarsdottir \& Elklit, 2004; Briere \& Elliott, 2000; Caldera, et al., 2001; Chou, et al., 2004; Jones, et al., 2002; Suar, et al., 2002). Another noteworthy finding includes the influence coping strategies and world outlook have on recovery from natural disaster. Literature supports that specific coping styles and assistance received from survivors following natural disaster may influence overall psychological recovery with less negative psychological and physical effects reported. (Bodvarsdottir \& Elklit, 2004; Caldera, et al., 2001). Finally, it is important to mention that some authors report that exposure to natural disasters may continue to influence survivors for many years after initial exposure and 
the type of disaster is less predictive of long-term trauma as opposed to resultant property and/or home loss that have occurred (Briere \& Elliott, 2000). This finding is critical when considering the influence material losses may have on psychological functioning following disaster.

Qualitative and multi-method findings. One of the most significant findings noted from this review of literature involves the importance of perceived sense of place not only in disaster survivors but in those persons who recognize potential threat to the physical location or home in which they reside. This is evidenced through findings that acknowledge extreme concern regarding coastal land loss, continued establishment within home residence despite potential unsafe living conditions during and after disaster, and in the demonstration of resilience, pride, and compassion during the rebuilding process following disaster (Burley, et al., 2007; Raholm, et al., 2008; Tapsell \& Tunstall, 2008; Yoon, 2009). Another important finding involves the survivors' capability to view the experienced disaster as a positive life influence allowing for personal growth and different view of self and the world (Ibanez, et al., 2004; Raholm, et al., 2008). This point is particularly important in understanding how disaster survivors' cope through the sharing of their stories as they continue to rebuild their lives and homes.

The preceding literature review served as the initial groundwork for continued investigation on survivor experiences following catastrophic property and/or home loss from natural disaster, particularly flood. The study provides a clearer understanding of the meaning of catastrophic loss following disaster from the survivor's perspective. Specifically, those who experienced loss from flood were provided a forum to voice what matters the most regarding the lived experience of surviving a flood. 


\section{Chapter 3-Method}

This chapter serves as an overview in describing and explaining the methodology selected for data collection and analyses for this study. Philosophical underpinnings of the method will be discussed further in relation to the study methodology. Target population, recruitment of participants, ethical considerations, analysis, and maintenance of rigor throughout the study are discussed in this chapter. In keeping with the research question "What is the structure of meaning in the experience of living through a flood situation where there is catastrophic loss?” the phenomenological method selected fits with the purpose and scope of this study.

\section{Methodological Underpinnings}

An underlying premise of the phenomenological method is that of exploring the meaning of the phenomenon of interest as it is viewed by the person who has lived it (Connelly, 2010; Giorgi, 1985; Kleiman, 2004). This is the foundation that supports the selection of the phenomenological methodology for this study. Embedded within this method is the importance of hearing the voice of those who have lived through an experience and allowing the focus to be on the perspective of the person experiencing the phenomenon (Koivisto, Janhonen, \& Vaisanen, 2002). In applying this method, the researcher examined the essence of an experience through story, which provides insight into the phenomenon being examined and the meanings associated with it (Connelly, 2010; Kleiman, 2004). This aspect of application aligns with story theory in relation to both the data collection and theoretical lens. 
Another premise of the phenomenological method is that it is descriptive in nature. This description is critical when communicating meanings associated with the phenomenon of study. The description is essential for a deeper, more meaningful understanding of the phenomenon which arises from a person's awareness or consciousness (Giorgi, 1997, 1985). In attempting to grasp such an understanding, a story depicting the lived experience assists in the description of the phenomena being explored. In describing the meaning of a story, the researcher must maintain sensitivity to what is important to the person about the phenomenon of study (Giorgi, 1997). Following this process, identification of themes may be made between and among the stories shared.

Another premise in using the phenomenological method involves setting forth and clearly identifying themes following description of the phenomenon of interest. This practice is important during the analysis of data, at which point themes are initially identified, allowing for the essential characteristics of the phenomenon to emerge (Kleiman, 2004). The identification of these characteristics collectively, serves as the structure of the phenomenon under examination and constitutes the findings of the study (Kleiman, 2004). Upon confirmation of the structure of meaning of the phenomenon, the researcher can elaborate and disseminate this structure to others.

Finally, the last premise of the phenomenological method is to clarify the structure of meaning of the phenomenon through articulating the path of analysis when making the study findings public. It is important for the phenomenological method to be trustworthy, which requires planning and systematic analysis of themes extrapolated from the data (Koivisto, et al., 2002). Providing clarity for the precise method of data gathering, subsequent analysis, and 
following through with the method is important for study auditability. This clarity of the method permits the entire research process to remain visible and auditable, thus demonstrating trustworthiness of the work (Bailey, 1997).

\section{Method}

Participants. The sample for this study included eight individuals who have experienced substantial loss of material possessions and/or residential property due to a single flood event. The event chosen for the recruitment of participants was the flood that occurred in the Western Pennsylvania and Northern West Virginia regions as a result of torrential rains caused by Hurricane Ivan in September, 2004. According to the National Weather Service Forecast office in Pittsburgh, PA (2010), the largest 24 hour rainfall total of 5.95 inches was officially recorded at Pittsburgh International Airport on September $17^{\text {th }}$, 2004. Some areas of the region received overall rain totals of 9 inches, leading to massive flooding.

Inclusion/exclusion criteria. Criteria for inclusion of participants in the study were: age 18 or older, ability to speak fluent English, free of any condition producing impairments in cognition or speech, and existence of material and/or property losses from flooding during the Hurricane Ivan storm. Participants verbally verified displacement from the primary residence for a minimum of 8 to12 hours. This verification was important in determining material/property damage severity when considering catastrophic loss. Damage and losses were a direct result of the flooding that occurred in the region, and not by other weather-related events such as wind or lightning. Sample size determination was dependent upon the collection of data sufficiently needed in answering the research question (Marshall, 1996). The number of subjects needed for a 
phenomenological study varies between 2 and 10 depending on the adequacy of data (Parse, Coyne, \& Smith, 1985 p.18). Data adequacy comes with the richness encompassed in detailed stories of the lived experience and redundancy. Redundancy is the repetition of participant statements noted across all stories regarding the phenomenon under study.

\section{Ethical Considerations}

Prior to beginning the data collection process, approval was obtained from the Institutional Review Board (IRB) at West Virginia University. Applications for approval were submitted according to IRB requirements. Application for approval met the exempt review since data were collected via audiotape and potential participants were subject to no more than minimal risk.

Recruitment and enrollment procedures. Following IRB approval (appendix A ), recruitment of participants took place in cooperation with the American Red Cross of Southwestern Pennsylvania's Disaster Services Volunteer Coordinator who serves as a liaison with Disaster Action Team (DAT) volunteers. These volunteers were solicited because many were personally affected or knew of someone who experienced catastrophic loss as a result of the flooding from Hurricane Ivan. Meetings were held with disaster volunteers, and the Red Cross Disaster Coordinator to: answer any questions, solicit assistance for participant recruitment, and exchange contact information. Written information which explained the purpose of the study and contact information for voluntary participation was electronically sent to the DAT volunteer coordinator and other potential participants as requested. Possible referrals from those who chose to participate in the study and others who knew about the study were encouraged 
throughout the recruitment process. All persons interested in participating in the study contacted the researcher via telephone during which all questions were answered and a meeting time and place were established. On the scheduled meeting day and prior to beginning data collection, an informational letter was provided to each participant. (Appendix B). This letter provided a brief explanation regarding study purpose, short description of the methodology being used, and explanation concerning maintenance of confidentiality relating to management of data. Further questions were addressed by the researcher as warranted.

\section{Data Collection}

Data were collected from participants who agreed to participate in the study. Demographic data including age, sex, marital status, and time of displacement from residence were collected prior to beginning the conversation. Conversations were loosely structured using story path to allow participants to tell their flood experiences beginning with the day of the flood, moving to the rebuilding process, and finally to present and future times. The lead question used to begin the conversation with all participants was: "I understand that you were involved in the flooding that took place as result of Hurricane Ivan in 2004. I would like you to think back and tell me how the day began?”As the stories unfolded, other questions were used to move the participant along the story path which included: "What do you remember next?”, "What changes have occurred with you since the flood?” and “As you look back, what is different for you?”

The story path assisted the researcher in gathering the participant's story through all facets of the story experience. This approach presumes the understanding of a present health challenge arises through past events associated with that health challenge, as well as future hopes 
envisioned by those experiencing such a challenge (Smith \& Liehr, 2005). Data were audio recorded using a digital recorder in entirety, and notes were written as needed. Conversational data including researcher questions were transcribed verbatim by a hired transcriptionist. The researcher listened to all audio recorded interviews to confirm accuracy of the transcripts prior to erasing interview data. Written transcripts were labeled with an identifying code to maintain anonymity of the study participant.

\section{Data Analysis}

The method for data analysis encompassed distinct phases which are congruent with both the phenomenological method of inquiry and story theory. Phenomenological phases according to Giorgi (1985) include getting a sense of the whole, discriminating meaning units focusing on the phenomenon under investigation, transforming the participant's language on the phenomenon of study, synthesizing consistent statements regarding the participant's lived experience, and synthesizing general statements from multiple statements.

Using this approach for analysis, each transcribed flood story was examined in its entirety. By reading each transcription, as many times as needed, a global sense of the data was acquired. This process is critical in determining how various parts are identified and in the discrimination of meaning units (Giorgi, 1985; Kleiman, 2004). Through careful and repeated reviews of each transcription, alterations or shifts in meaning identified by the researcher represented a meaning unit and were expressed in the participant's own words (Giorgi, 1985; Kleiman, 2004). 
Transforming participant language of the phenomenon by the researcher to identify themes is essential in moving the analysis process forward (Smith \& Liehr, 1999). A theme is defined as an aspect of the structure of meaning in the lived experience (van Manen, 1997). In this phase, general groupings or categories were identified from the story meaning units and through reflection and imaginative variation. The researcher expounded upon these groupings to a depth that transformed appropriate dissemination within the discipline in which the researcher belongs (Giorgi, 1985). In the context of this study, the disciplinary perspective is the human health experience. Synthesizing consistent statements regarding the participant's lived experience align with the integration of individual and collective stories. In this stage, the structure of meaning is identified in relation to the phenomenon of study in individual and collective transcriptions or stories and communicated to others for critique and/or confirmation. The synthesized structure of meaning represents the findings of the study.

In this study, the phenomenon of catastrophic loss following flood was analyzed using phases of phenomenological inquiry and analysis. It was critical that the phases were clearly and consistently followed throughout the data collection and analysis process. This method of data analysis was essential in providing rigor for explication of findings.

Procedure for data analysis. The following five phases were included in the analysis of data. Upon provision of the informational letter, the participants were invited to tell their stories using a story path approach. The story was tape recorded and the following phases were followed in the analysis of data:

1. Getting a sense of the whole by dwelling with each story. 
2. Discriminating meaning units to organize the beginning, middle, and end of each story.

3. Transforming participant language to the language of the researcher.

4. Identifying themes of the lived experience.

5. Synthesizing a structure of meaning of the lived experience.

These phases are an iterative process, repeating back and forth in the analysis of the data. Each phase moves along in the analysis process ending with the explication of the study findings.

\section{Maintaining Study Rigor}

Maintaining study rigor is dependent upon the researcher’s ability to understand and adhere to a method to insure study trustworthiness throughout the research process. The exact way to best accomplish study rigor has been the subject of debate within the literature (de Witt \& Ploeg, 2006). During the data analysis phase, it is imperative that the researcher is able to defend specific interpretations made as being appropriate and relevant to others within the research community, through feedback from others (Akerlind, 2005; Graneheim \& Lundman, 2004). This feedback may be acquired through critique from interviewees, researchers, or professionals within the discipline or area of inquiry. It is equally important for the researcher to clearly convey the steps for data interpretation to readers by offering detailed explanation of each step and providing appropriate examples (Akerlind, 2005). 
Graneheim \& Lundman (2004) propose that the concepts of credibility, dependability and transferability be used to preserve trustworthiness during the qualitative research process. Creditability refers to the belief in how suitably the data and subsequent analytic processes address the intended study focus. Dependability considers the degree to which data may change and the researcher's decision-making processes over time during the analysis phase. Lastly, transferability is the extent in which research findings may be transferred to other populations or settings (Graneheim \& Lundman, 2004).

The audit trail further supports rigor and credibility of qualitative research. Auditability is accomplished through the provision of evidence that provides other researchers and potential reviewers with a verifiable path the researcher used during data collection and analyses (Robinson-Wolf, 2003). This evidence is provided through organization of raw data which substantiate interpretations of the researcher and contributes to the investigator's persuasion that the study is logical, unbiased, and creditable (McBrien, 2008; Robinson-Wolf, 2003).

Regardless of the method that is used to uphold rigor, it is essential that clear communication of each facet of the data analysis process is carried out. Rigor within this study was maintained through clear explanation of each phase of the data analysis process using the phenomenological approach outlined by Giorgi (1985) and story theory (1999) as theoretical guides. Feedback and critique were solicited by dissertation committee chairperson during the analytic processes to assist in ensuring study rigor and trustworthiness. Additionally, raw data transcription and documents illustrating the analytic processes were organized systematically and color coded, which have been maintained throughout the study and are available for review supporting auditability. 


\section{Summary}

This chapter summarized the foundation for the methodology selected for the data collection and analysis processes used in this study. Details regarding participant recruitment, ethical considerations, and maintenance of rigor throughout the study were explained. Through these activities, the findings from this study can be discussed in the following chapter while maintaining the trustworthiness of this research. 


\section{Chapter 4-Findings}

Within this chapter, the study findings that describe the structure of meaning in stories from those who lived through the experience of a flood event where catastrophic loss had occurred are presented. The study was guided by story theory (Smith \& Liehr, 1999) and the phenomenological method of inquiry adapted by Giorgi (Giorgi, 1997, 1985). Data characterizing participant demographics are summarized and specific methodological procedures used for data collection and analyses will be discussed. Lastly, participant description validating the themes in the structure of meaning of the lived experience of catastrophic loss following flood are provided.

\section{Recruitment Process}

Following IRB approval as an exempt study by West Virginia University in November, 2010, recruitment of participants began. Recruitment letters were distributed through the American Red Cross DAT (Disaster Action Team) coordinator in DAT meetings and through electronic mail to all Red Cross DAT volunteers. Additionally, through informal discussion and distribution of recruitment letters to colleagues, friends, and family members a total of eleven individuals contacted the researcher agreeing to participate in the study. Meeting location, time, and date for the story collection were established between the researcher and each participant. Ten participant meetings took place between the time periods of $11 / 12 / 10$ and $2 / 12 / 11$. One conversation and subsequent flood story was gathered on 8/11/09 as a pilot to gain a better understanding of the story path method and was included in this study for data analysis. All conversations except one were conducted in a private home at a mutually agreed time and date. 
At the request of one participant, the meeting with the researcher took place in a neutral location, using a private conference room in a local municipal building.

\section{Data Management}

Prior to beginning conversations, all questions regarding study purpose and story gathering processes were answered by the researcher. Conversations were audio taped in their entirety using the story path process, a facet of story theory (Smith \& Liehr, 1999), leading the participant through the flood experience from the beginning of the day, through the flood event and rebuilding process, and finally to the present and future time periods. Several open-ended questions were used throughout the conversation to assist the participant through each aspect of the story path. Immediately after completing his or her conversation, each participant was given a \$25.00 gift card for sharing their flood story.

Each story was transcribed verbatim by a transcriptionist and later verified for accuracy by comparing the transcript with the audio taped interviews. Following the verification of the raw transcribed data, the audio taped interviews were deleted from the researcher's digital recorder to further ensure confidentiality. To delineate short pauses in the participant's speech, a series of periods (...) were used in the story text. Participant anonymity was maintained by assigning each story a number and letter. Story codes were matched with participant phone numbers and kept in the event future communication was needed. These numbers were secured in a private area in the researcher's residence. This identification process remained throughout the entire data collection and analyses process. To insure participant anonymity, phone numbers and story codes were destroyed after the researcher completed all processes of data analysis. 
Eleven stories were gathered. Two of the eleven transcribed stories were not used in the final data analysis. In these two stories, the participant's spouse was present during the conversations. Intermittent interjection by the spouses allowed for dual dialogue during the story gathering process thereby making the story a mixture of two voices. The eleventh story was gathered by the researcher from a single participant. After analysis was completed on eight of the stories redundancy of thematic content came to light and the decision was made not to include this eleventh story in the data analysis.

Length of the eight audio taped stories ranged from 16 minutes to 73 minutes with a mean length of 40 minutes. Transcribed pages of the entire interview text between participant and researcher ranged from 7 to 22 single spaced pages. All participant stories contained great detail in relation to specific events surrounding the flood experiences that happened approximately six years ago in September, 2004. Additionally, participants demonstrated significant interest in sharing their stories and spoke freely with the researcher.

\section{Participant Demographics}

The eight participants ranged from 25-80 years of age with the mean age of 45 years and all living within a 30 mile radius of Weirton, WV. The sample included five females and three males. Six participants were married and two were single at the time of the story collection. Four participants resided in the Northern West Virginia region with the remaining four participants living in the Western Pennsylvania area. All participants resided in the same general locale following the massive creek and small stream flooding precipitated by the heavy rains from Hurricane Ivan in September, 2004. Five participants remained in the same residence that was 
involved in the flood and three moved to different homes. The displacement period from home ranged from approximately twelve hours to six months in length.

\section{Data Analysis Process}

In keeping with the essence of phenomenological inquiry which examines a phenomenon of interest and associated meanings as it is experienced by the individual, data analysis was completed. The analysis of data was completed using specific phases that parallel with the phenomenological method of inquiry adapted by Giorgi (Giorgi, 1997, 1985). The data analysis phases were followed to ensure the credibility and trustworthiness of the findings. The key phases relevant to the phenomenological method of inquiry used in the data analysis processes will be explained next.

Getting a sense of the whole by dwelling with each story. Transcribed data for each story was read multiple times to identify shifts in the story. Shifts represented another event in the experience of living through the flood situation. This activity assisted the researcher in obtaining a comprehensive sense of each individual story. Reading and re-reading each story enabled the researcher to gain an understanding of the participant's lived experience of a flood event where catastrophic loss had occurred. This process was repeated for each of the eight stories.

\section{Discriminating meaning units to organize the beginning, middle, and end of each}

story. Meaning units or designated changes in the meaning of the situation within the story text were identified by the researcher. Identified meaning units in the language of the participant were placed in serial order reflecting a distinct beginning, middle and end within each story. 
Repeated references of the same subject matter were removed when organizing the meaning units into serial order. To further the analysis process, meaning units were arranged in a single column to move onto the next phase.

Transforming participant's language to the language of the researcher. The researcher again dwelled with each meaning unit to ascertain language spoken by the participant that described the lived experience of catastrophic loss from flood. The participant's language was lifted to higher level of discourse using reflection and imaginative variation. These activities assisted the researcher to reflect upon each meaning unit identified in the participant's language. This reflection facilitated the discovery of the search for essence in the meanings of the phenomenon being explored enabling transformation from the language of the researcher. Through imaginative variation, the researcher envisioned the participant's description in an attempt to ascertain the meaning of the experience. The obscure participant language is then transformed to a depth appropriate for understanding the search for essence related to the phenomenon of interest (Giorgi, 1985). The transformed units were documented in a corresponding column next to the participant meaning units and completed for eight participant stories. This phase represented the beginning theme analysis for the individual stories.

Identifying consistent statements of the transformed meaning units. The researcher dwelled with the meaning units in the language of the participant and the language of the researcher to indentify the inherent main idea in each unit. These statements or main ideas evolved primarily from the transformed meaning units in which each story was organized. These statements were further interpreted to identify themes in the structure of meaning. 


\section{Synthesizing themes in the structure of meaning of the lived experience. The}

researcher then dwelled with all of the phases of analysis up to this point in order to synthesize fourteen themes across all eight stories. These actions helped establish the structure of meaning that is a consistent description of the lived experience of the phenomenon being explored. Lastly, initial themes were revised to a higher level of abstraction to better reflect the full description of the structure of meaning of the lived experience of a flood event where catastrophic loss had occurred. This structure of meaning is encompassed the findings of this study and are presented below.

\section{Study Findings}

The structure of meaning identified in the stories examining the lived experience of a flood event where catastrophic loss had occurred encompasses the following themes:

1. Beginning as the usual ordinary day despite heavy rainfall.

2. Increasing recognition of rising flood waters as communicated by flood warnings via family, friends, and airwaves.

3. Growing apprehension when faced with rising flood waters and the likelihood of damage yet to come.

4. Shifting to concentrate on what needs to be done to secure possessions and the safety of pets in the midst of the rising waters.

5. Watching the power and destruction of the rising flood waters in agonizing disbelief. 
6. Retreating in haste from the danger of the rising flood waters to the safe reprieve of higher ground and relative's homes.

7. Seeing yet not believing the chaos and expansive devastation when returning home.

8. Coming to know the breadth of destruction and substantial ruination of belongings and property.

9. Contemplating the overwhelming task to restructure life and home to what once was.

10. Overwhelming heartfelt gratitude for the assistance of others to reestablish home and property destroyed by the flood waters.

11. Taking on the effort to rebuild with energy and commitment.

12. Making deliberate choices about future life decisions in light of the flood experience.

13. Living an always present uneasiness when there is heavy rainfall.

14. Reflecting on a changed life perspective that surfaces in day to day living.

The structure of meaning in the stories examining the lived experience of a flood event where catastrophic loss had occurred is illuminated through the themes collectively across all eight stories. Each theme represents an integral part of describing the structure of meaning during the entire flood experience, and holds equal importance. Specific participant examples that best reflect each of the identified themes are described below. 
Beginning as the usual ordinary day despite heavy rainfall. All participants described the day of the flood as beginning in an ordinary manner despite the rain which began in the morning hours. Many accounted their daily routines by attending school, work, or by completing everyday errands. Accounts of routines included:

The day began by getting up and like a normal day and getting ready for work. I actually went to work that day, and I had court. I can remember I was working with children with the Florence Crittenton home with the kids and I had to go to court with one of my girls and I can remember it was just raining and raining and raining and I just oh... it was so annoying and I was so looking forward to going to the beach.... I can just remember walking in the courthouse and I was completely drenched and we were laughing about it and I just kept saying “Oh..I'm going to the beach thank goodness.”

Another participant expressed how the day of the flood began by completing a shopping

errand with her husband:

Ok, basically I remember it was Friday and I'd been off work. I got married five days before that on Sunday and we worked all week to get the house cleaned up, so.. my bunch of debit cards and stuff to use from the wedding. So we decided to go out to Wal-Mart and just do some final shopping and finish up with food and get everything ready so, about ten o'clock we went out to Wal-Mart and did a big shopping, probably $\$ 500.00$ worth of food and groceries and everything and came back, put everything away, and it had been raining that day, and nothing, you know, just a lot of rain but nothing we thought was too crazy.

Another participant recalled how the day began with the usual routine of attending the local vocational technical school as scheduled:

Well I just woke up like any other day, you know. I was in high school then and just went to school like normal. It was raining that day.

The preceding description reflects the acknowledgement of the rain being an ordinary occurrence without concern as the day began. As the day progressed, participants were alerted of the rising flood waters. 


\section{Increasing recognition of the rising flood waters as communicated by flood}

warnings via family, friends, and airwaves. All participants recalled receiving communication

by loved ones or via television warnings of the flooding near their homes as described by the

following statement from a participant:

After I was out shopping, I don't know if it was around noon or one o'clock in the afternoon....kind of early afternoon... my mom called my cell phone and asked where I was...told her I was at the store still and she said I needed to get home because one of my neighbors had called her looking for me and said there was water like at the front door of the house, and at the garage door at the house.

Another participant recalled hearing about the impending flood activity through the local

television station as stated below:

Okay, this is funny, well it started to rain and they were calling for flood warnings and I was checking the TV because they were doing early dismissals on the schools, and they had said or no, I don't know if I seen Bethany; my son was going to Bethany at the time, and I don't know if I seen it or not but I was trying to get a-hold of the school....

Several participants expressed that they received phone calls from loved ones regarding

the rising flood waters, but not yet feeling a sense of urgency as described by this participant in the following statement:

So, I went back to work. I went upstairs on the unit and my boyfriend at the time, he lived up the street... and he called and said, "Hey, I came down your house to check on your house, 'cause everything is pretty wet, you know, it's like laying on the street.” And I said, "Okay.” And he said, "I'll call you back.” So about fifteen minutes went past and he said, "You know, there's water in the front street." And I said, "What do you mean, in the front street?” And he said, “Oh, it's like down by the Fire Department.” And I said, “Oh that happens all the time. It's no big deal.” 
Another participant recalled that she too, was not overly concerned following notification from her loved one regarding the rising creek waters located behind her home as evidenced by the following statement:

I can remember my husband calling me and saying you know... it looks like it's pretty bad, the creek might be...the creek might come up and might flood, and I'm like...ok...well....that's fine...you know...I am not thinking (laughs) that it is going to have any... any effect on our house. I can just remember that he [husband] called and said "you are going to have to get home a little sooner, I think we're going to have to clear out the garage, get the cars out...you know...just to be on the safe side.”

Five participants began to experience difficulty navigating the roadways as they attempted to return to their homes as described by the participant:

I'll go home, but I was coming down 65. They had it blocked off already, so I made a right off of the main drag, and I'm looking and seeing no, this road is closed, this road is closed. It was hard getting here and I was thinking, "What the heck?” So the roads were, they were wet, I mean, Camp Horn Road was really wet, and the only way I could get here was to come down past, a Giant Eagle and then go up over by the school and cut down onto Crawford. But every place was closed.

Another participant remembered the difficulty that was encountered in trying to return home to check on the imminent flooding as evidenced in the following:

So I left Canonsburg, Indian Creek Road. I tried to get to Oakdale. I came down 79. I tried to work my way through Millers Run Road in South Fayette; it was all over water. So I went down 50, all the way to Gladden. Worked my way...all the way up through back roads that I know. I got up to the backside of Sturgeon, and tried to come in that way. They wouldn't let me come. So I went all the way back out toward McDonald.

The preceding excerpts represent the challenges experienced by the participants when attempting to navigate back to their homes after being notified of the rising waters by friends, families, and via television. While efforts to return home continued, recognition of the situation gave way to increased apprehension of what was yet to come. 


\section{Growing apprehension when faced with the rising flood waters and the likelihood of}

damage yet to come. The level of concern increased significantly following the participants

return to their homes. Many expressed confusion and sense of urgency as they began to witness

the rise of the flood waters around their homes as described by this participant:

When I got to the house, what I saw was about three feet of water on my garage door. So, I didn't want to open the garage door because everything actually would come gushing in. Didn't want to open the front door-same reason, and our house sits level with the road. So, I was waiting for my husband to come....he worked 15 minutes away at that point too. I stood out front and waited, saw him come on to the street and told him to take his car across the street to his mother's and leave it there because he couldn't get down the street either, so....he did that and came running back and we stood in front of the house saying "What do we do? How are we going to get into this house?"

Another participant expressed similar feelings while attempting to reach his home as evidenced in the following statement:

And I'm watching the waves hit the bridge and they moved out, what kind of thing we had on the bridge, it must've been big plates on there [bridge] and it moved them, it moved them and I'm looking at my house, over here, and I'm thinking, "What the heck am I gonna do?”

One participant described the rapidity of the unfolding events and increasing uncertainty

after attempting to reach home as the flood waters began to quickly rise:

...so [participant] went up and got her [daughter] out of the school and were, was bringing her down like, from the school and when we got to, like probably this where we lived was on the valley behind the police station and it was probably.... I don't know...a big area probably, I don't know, what it was, 300 yards in a gully and we got to the top of the thing and we looked down at the hill and there was our car sitting and the water was up to the doors of the car and this whole thing, and we were like, "Wow, that's really you know," .....

Shifting to concentrate on what needs to be done to secure possessions and the safety

of pets in the midst of the rising waters. As the seriousness of the situation began to solidify, 
all participants described the need to secure or remove belongings from their homes as described by this participant as she and her husband entered their home which was beginning to flood:

I came in through the kitchen window, and then I opened the French doors and let him [husband] come in and what we came into was...water on this main level, but just you know... an inch or less...not very much but all the water was traveling across the floor and going into the family room, laundry room, and bathroom that's down there [lower level of home]. And that was gradually filling up, so we just went and at that time our kids were much younger and had a lot of toys and video games and things like that so we started grabbing them. And the computer...you know...things like that we thought, ok...we don't want water. We don't want these things to get......ruined. We had no idea how much water was going to come, how long this storm was going to stay...you know kind of over top of our heads. And we just started.

Another participant found it necessary to enter her home in the midst of the rising flood

waters to remove a few personal items as she described below:

I remember thinking, "Oh.” I remember thinking, like, "I better go in my house.” Or I needed my contacts, that's what I needed "cause I had my glasses on. I was like, "I need my contacts, you know, I can't see.” And so I went in and the electricity was out. I felt around, got my contacts and by that time I was able to look out my back doors...I had sliding glass doors and a deck on the back. And it was, probably, it was probably about 7 or 8 feet high. And the creek was probably about a foot underneath of it.

Several of the participants had animals located in their homes and returned to rescue their

pets despite the growing danger of the situation as described below by a participant:

The road at this time had been shut down by the police and fire department, 'cause all of Camp Horn Road was disaster, see. And the fireman came over and told us to evacuate and I says, "Well I have," at the time I had four dogs here, and they says, "Well leave them." And I says, "Oh no, I am not leaving my animals," I said, "I'll stay in this house and die with them if that's the way it's supposed to be." So, they didn't argue with me at that point and we got our dogs, and put them in our blazer and had already called Animal Friends when they were down on Penn Avenue at that point, and they made some room for us to bring the dogs down and put them in bigger cages down there. 
Other participants found themselves or loved ones in extremely hazardous circumstances as they attempted to move their pets to safety as described by another participant:

So I got up by the highway, I started coming down this road and I thought I passed my boyfriend. And I stopped 'cause it's pouring down rain there. You can't see to even drive. So I stopped and the car backed up so I knew it was him. He gets out. He's screaming at me, "Everything's gone!” And I'm like...he's bleeding, like on his face and his arms. And he has a t-shirt and like, sweatpants on and we're standing in the rain and I'm screaming, "What the hell's gone? What the hell's gone?" And he's like, "The whole house is gone." And I'm like, "What did you get?" He's like, “All I got were your cats." So I looked in the front seat of his car. There's my old cat. He's all white, but he was black. He looked like coal. He was laying on the floor blowing bubbles of water out of his nose. And my kitten, she was only, like, a year old. She was sitting on the back of the car. And she's just soaked. And she's shivering. I said, “Alright, they're safe.” I said, "I don’t care about anything else.”

Another participant recollected her experience in trying to move her pet from her flooding home to safe ground in the following description:

Roxie was a puppy and we were almost swimming across this back yard to get to this wall to get out of there, and I dropped the puppy, I thought, "Oh," and I was like, "Please God take everything else but let me save the puppy,” so I grabbed her by the tail and I threw her up on the hill and we got up there.

The preceding descriptions characterize the strong attachment between the participants and their beloved pets. In the face of growing uncertainty regarding their own safety as conditions continued to deteriorate, participants were committed to insuring the safety of their pets regardless of the potential danger they faced the power of the rising flood waters.

Watching the power and destruction of the rising flood waters in agonizing disbelief.

All participants described the experience of watching the flood waters rise with its astonishing power and fury. The degree to which these experiences were described varied. However, all 
participants were impacted as they witnessed the height of the flooding. One participant described her experience of being in her vehicle when the massive flooding was at its height:

I can remember turning on to Washington Avenue and then on to Valley View, which was how you got to my house and it was at that point that the creek must of broke or whatever you want to call it, that it actually flooded and it started to come in and it started fill up my car. So, I was in my car and I couldn't get out of my car my...my you know this car is filling up and my horn is actually blaring because obviously the electrical was starting to short. For some reason one of my husband's friends was right near there..he lives nowhere near there...I don't know why he was over there.. (chuckles) I guess just to help... and he actually...you know, they...him and somebody else got me out of the car, and we ended up pushing the car up to get it out of the way, and I can just remember...I was like oh my gosh...how am I gonna tell my husband that the car is ruined because I thought he is never going to believe me that it happened down here, and I was only a few seconds away from the house but it wasn't clicking that hello...this is what your house is going to look like...like this...you know...this is what your everything. So, I walked home and I can just remember my husband was like... what.. "Where is your car?" "What happened?” and I told him what happened and he was just devastated and I can remember seeing him standing there trying to catch things as they were floating by...like just things of his that were like his...oh my gosh....there's my whatever that was floating in the garage.

Two participants described the force in which the flood waters raged near their homes as

they watched in amazement. One participant described what the raging flood waters looked like:

That main street going through there...I mean that water was so high...There were jet skis, there were boats, there were the great big trash bins from apartments that were down the street. Everything was just...it was...it was surreal...it was just crazy. You're looking at it...you can't imagine what's going down in this water. You know... and then all other kinds of debris, you know, tires, hoses....

Another participant described what was witnessed as stated below:

I could see my house, like I say, the street wasn't all, you know, but as soon as you got down here to the bridge, you know what I mean, it was just up on the bridge, the water, man it was just coming and it was strong! It was, you know real loud, real loud and so I’m thinking, "What am I gonna do?” You know? 
Three participants experienced complete catastrophic losses of their home and a large proportion if not all of their possessions. One participant recalled witnessing the complete loss of her home and possessions from the ravaging flood waters:

And I was walking down the road kicking stones. I was all mad and then I was down at the end of the road, and my neighbor came running down and he was waving his arms like, hysterically, he was going, "Get away from the bridge, get away from the bridge. Your house is coming!" And I was like, totally like, "What?" And I turned and I remember looking, I could literally, like my trailer, like this big submarine going like this (gesturing with arms outstretched), in the water and then I started to see my son's things come up from underneath of it. And I just, I just lost it. I just like, hit the ground. And I remember my dad picking me up and being like, "It's okay. It's okay, you know. At least you weren’t in it.”

Unable to reach her home, another participant described her experience as she and her

father watched the devastation of the entire community in which she lived:

Yeah. The water, it was still pouring down rain. The water was still everywhere. So we got down there, and then there was no way I could get to my house. Some firemen, the guys said go home because I was hysterical. They’re like, "You know," to my dad, "Take her home because she's no good to anybody." 'Cause I was all worried about my house. So, I remember standing on the bridge. We were standing on the hill, he's [emergency response officer] in charge and he says to me, "You need to go home." He's like, "You're no good.” "Cause, I mean, I was crying hysterically, you know, like, "Look at the town. Everything is under water.” The whole gazebo, all the bars, it was up to the roofs.....

Retreating in haste from the danger of the rising flood waters to the safe reprieve of

higher ground and relative's homes. All participants were eventually able to safely leave the flooding areas and move to higher ground, and find respite in homes located in a safe area. This participant described the experience of leaving home, and moving to higher ground to awaiting family members:

We were pretty much like the water was like up to our chest and we were walking. So we kinda walked up the hill to the interstate and he met us up there, my father-in-law, and you know basically we had to wait...I mean we had to, we didn't know what was 
happening to our house, we didn't know what was going on. We ended up...it took quite a long time, but we ended up you know... coming back to his parents' house.

Another participant described the immediate retreat from home necessitated by the rapidly moving flood waters entering the premises as evidenced below:

So I went and you know, my husband said we had to get out of there [house] so we opened the back door of the house to get out of there and it looked like, it was waist high with water just coming at you with all kinds of crap, like trees and stuff... my husband got the old lady next door and we started walking her up there [higher ground], then I remembered that my keys were in the pants I had on that were gone, and I had my shoes on, so we ended up you know, got up top the hill then, and we just watched the whole valley fill, I mean it was just a huge amount of water, didn't even know where it came from. And then we ended up we got a car, or something, and then got my spare keys, and then took everybody out to my Mom's out in Cannonsburg, you know, 'cause we couldn't stay in that place.

Another participant recollected the experience of leaving home to the comfort of his grandmother's house:

We hung out for a little while; a couple more hours and it seemed to stop rising. We kept marking the wall. It would rise up a little bit, and a little bit more and a little bit more, but then it finally leveled off for an hour...didn't really go anywhere, then actually started to drop back down. So we went up to my grandma's. We stayed up there at my grandma's for the night. Actually, a couple nights... for about a week.

Another participant talked of the kindness of a stranger that he encountered when unable

to return home or contact loved ones as described below:

Whenever I was there [local eatery on higher ground] a guy told me, he says "Look, I live up on top of the hill,” right up on this road here. It's a back road, I guess it's called the Old Camp Horn Road and it goes up and then he was on this side of the hill where he brought me in his house. He took me in his house, 'cause, man, if they ever get water up there [hill]. I stayed there overnight. I still didn’t know where my wife was. You know, I didn't have a cell phone, and she didn't know where I was. She couldn't, there was no way to get in touch with me. 


\section{Seeing yet not believing the chaos and expansive devastation when returning to their}

home. Within 24-48 hours after the flood began, all participants were able to return to their homes to begin assessing the damage. Unsure of what they would find, many experienced feelings of being overwhelmed as they witnessed the destruction of their homes and properties as described below by this participant:

I thought we are in so much trouble, and I hadn't even been in the house yet. I'm just looking at the outside, that you don't even need to really live...you know...my kids can...play in the front yard or ride their bikes or whatever...but...I just...I think I felt overwhelmed is what it was. It was just...it was just a mess (voice quiets). And I didn't know...like where to start, and I thought we're two people you know...we're two people (crying) and what are we gonna do? So, I know I stood there, I know I was in shock...

Another participant described the experience of returning home in the early morning

hours after the flood waters began to subside:

My dad and I went down, we parked, probably two miles from the house, 'cause it was like a hill. We took garbage bags with us, we waited; we went down, we met the firemen. They said, "You know, you're [participant] a police officer, go ahead.” So, we waded through all the water. It was about waist high. We got to the house. The windows were all blown out of the house. The doors were ripped off the house. So, we just kinda stood there. And I remember, looking at my dad and I started crying and I'm like, no I was fine. My dad looked at me and he started crying and I've never really seen my dad cry. And I said, “It’s going, we're gonna be okay.” And he was like, “I hope so.” He’s like, "I can’t believe this."

Another participant described the feeling of being out of control as she waited to return

home at daybreak:

So we just, you know, we had waited there [mother's home] probably, I don't know, maybe like two hours, and there was just nothing we, you know, it was useless, there was nowhere to go, so we got everybody settled, and then we went back the next morning about six o'clock in the morning and all the water, it was amazing. It was down, it was probably on the ground around the place was probably a foot and a half or so, but everything was completely washed out from the water. Ended up being about two foot above me, but I'm probably five eight, so the water, on the basement was covered, and then the kitchen, living room, sun room, and a bathroom, was everything was, just yuck! 


\section{Coming to know the breadth of destruction and substantial ruination of belongings}

and property. In the following days after the flood, all participants were able to better examine the full scope of destruction caused by the now receded flood waters. One participant described the extent of damage assessed to the property where his home was located in the following:

Then the next day, came out in the yard and was looking around, and I did go up on the hill at that point 'cause I didn't feel as though it was a hazard. I went up to see the damage, 'cause you couldn't really see the damage to the property because of the lower trees, so you had to walk up in there and about midway up my hill, 'cause I sit on an acre and a half here, and probably half of it is woods up on the hillside and then the other half is our yard and our house. I couldn't believe it, it looked like a bomb had been dropped on the hill. This huge crater was up there and I literally walked into the crater and the earth line was up to my face, that's how deep it was. There was, at that time I counted six trees uprooted and flipped back and these trees were probably, between fifty to seventy feet high or maybe even more.

Another participant recounted the observations made as she walked through her home

and realized the complete devastation:

The living room furniture floated from the living room, through the dining room, through a kitchen... and like the recliner was in the laundry room. I'm not sure how it got there. The kitchen cabinets were all ripped off; most of them. The refrigerator was laying on its side with food everywhere. What laid on top of the counter because the water had subsided a little bit. I had a fish tank with beautiful fish. They were...the fish tank was on its side and all the fish were dead. And then, the living room, everything was not where it should be.

One participant recalled the confirmation of the complete loss of her home and

possessions and the significant destruction of her parents' home as described below:

My house was completely gone. There was nothing except for the cement pad that was in the front of my door. There was a cement pad. Everything else was gone. There was nothing. My husband's car was completely flooded. There was mud in it 'cause it was completely submerged. Where, see, my trailer was beside my parents', they had a big block garage, it was like 32 by 32 block garage. It was completely gone. It was knocked over kind of like on the side...the roof was completely off of it and the blocks were all down and everything. Their house had about... it had about 6 foot of water in it. I 
remember looking in, like the bedroom windows and just the dressers were all...they were upside down and stuff was just...papers were everywhere. They had like a latticework around their deck and just papers where the water just shoved the papers up against it. It was like a strainer, you know. (laughing) And...the refrigerator was, turned over. The table was all...up against the wall and chair, had a foot of mud through it.

\section{Contemplating the overwhelming task to restructure life and home to what}

once was. All participants reflected on their desire to recapture their lives and homes as they were prior to the flood and recounted the measures taken to return to a sense of normalcy:

I think that was it...the few days, the two, three, four days after. I mean all you were doing was cleaning, cleaning, cleaning and from...we would get up...I mean it was just nervous energy, we would be up at six in the morning. We'd be over there you know...starting cleaning, doing all kinds of stuff until the very late hours in the evening and I think a lot of it had to do with like...we were so convinced that we had to get everything back to the way it was you know, we thought that we could.

Another participant recognized that her life as she knew prior to the flood could not be

reestablished exactly however, she strived to regain a new sense of normalcy as described below:

My husband and I, we dated 18 years before we got married and no particular reason why we didn't get married just that we didn't. We sort of figured if we could live through that after we first got married that anything else was sorta like, “Eh”. It actually brought us closer because we had no choice but to you know, work together and, you know, keep on moving.

Finally, another participant remembered the agony of restructuring life six months after experiencing complete loss from the flood and the feelings resultant of longing for her life that once was:

It was tough. 'Cause we lived with my in-laws for six months, until we bought this house. But, it was really hard because here he [military husband] was gone for almost a year. He was gone for ten months, and we had all these plans when he came home. We were gonna go do this and we were gonna go do that. And we were gonna go see this and that, and that was all done. A lot of anxiety and just being... like, being in somebody else's house and just the differences in the people; like they would do things different than how I would do it at my house. Well my house was gone so I was very bitter, very angry. I 
would take it out on everybody. (laughing) I was horrible. I was a little bit selfdestructive.

Two participants expressed the importance of maintaining daily routines with their children in order to promote a sense of security through providing structure as the rebuilding process continued. As one participant described:

So we were out of the house for about 4 days after the flood by choice, came back for a night with the kids, you know...did like a little movie, popcorn, had the dogs and everything and then told them..."We're gonna to stay at Granny's, we'll come here and work during the day"... of course, the kids were in school, so, "while you're at school, Mom and Dad will come, we'll work on, you know... doing what we're gonna do to the house, we'll make choices together... and you go to school, do your job, that's your job...you make your good grades, you concentrate on school work; we'll worry about what needs done at the house."

Similarly, another participant recounted the need to reestablish a normal school routine

for her daughter:

I told them at work that before I could come back to work, you know, that I have to, I wanted to get a house for my daughter and wanted to be able to get her some normal stuff and then get her off to school and then I'd be back. I sent her the following Monday and that was only basically 'cause I needed something to do with her. I wanted to keep her, you know, regular life but we just sorta never looked back, we were like, you know, nothing we could do about this.

\section{Overwhelming heartfelt gratitude for the assistance of others to reestablish home}

and property destroyed by the flood waters. All participants reflected upon the help that was

given by friends, family, community agencies and complete strangers wanting to lend a helping

hand. This participant recollected the physical and emotional support received from friends,

family, and acquaintances in assisting with the clean-up efforts following the flood:

We stood there for about a minute or two and I heard someone say to me, "Hey...I came to help you," and I turned around and it was one of the parents from my kids' school. They're not in either of my children's class... her kids are just a touch older than both of mine...And I was like... Oh my God...that was so sweet. Here’s someone that isn’t one 
of our very closest friends...they're definitely acquaintances, and I would certainly help them if they ever needed anything... but that wasn't who I expected to be the first person that stepped in to say, "We came to help you." And they live up on a hill, so they were fine. (laughed). He said, "What do you need done?” And I just like needed...I looked at her, you know. I put my hands up and said, "I don't know." I'll never forget it...we were standing there on that side of the yard, and I was just...I don't know where to start...I don't know what to do... and I told her, "I haven’t even been in the house.” She said, "Well, let's go take a look."

This participant expressed gratitude with the outpouring of assistance provided by a

complete stranger as evidenced by the following:

I remember that day, so we were cleaning up down there and I had hip waders on and I was all full of mud but we had a lot of people helping us, so I went up to Shop and Save here in Bridgeville, and I was just walking through and it was almost like people were looking at me like I was walking through, I don’t know like, Viet Cong, or something, and a lady walked up to me and she was like, "Were you in the flood?" and I said, "Yeah, we lost everything," and she was like, "Well give me your name and number," and I'm like, you know, "Not now." So the lady kept pestering me so I did give her my name and number, and here this lady, she ended up calling me about three weeks later, two weeks later, maybe a week later or something, but she had given me, I mean, all kinds of stuff and all kinds of stuff to the neighbors, like furniture and any coffee pots and anything you can think of.

Another participant recollected the feelings of gratitude as a total stranger arrived to lend a helping hand:

But I couldn't get over the people that come down...there was a woman down here and she was a beautiful woman, and I'm looking at her. She's down on her hands and knees mopping my floor with rags and I says, "Do I know you?” No, she was from Sewickley. And she heard about it and she come up here. And she said, "I wanna do it."

This participant recalled the support received by the National Guard during the massive clean-up efforts as evidenced by the following:

National Guard helped us a lot too. They gave us, brought us food and ice water...a bunch of stuff all the time...every day. They came around every...three times a day and gave you a meal for your whole family. They were there, basically until they got the 
roads clear. And over by the church...no one could get to their home, so they were there for like, looters...make sure no one would go over there and steal stuff. But they stayed there all night and everything.

Taking on the effort to rebuild with energy and commitment. In the days and weeks following the ruinous flood, the depth of what was lost became evident for all participants. Immersed in the staggering thought of picking up the pieces, this participant described the experience of beginning the rebuilding process and the commitment established to regain her life once again:

I definitely think that all the work we were doing and all of the physical work...I had never experienced to that degree, I mean I had never...I was always like..you know, somebody else did that...or you know somebody else did it....but it was like this is mine. Nobody else can do it for you, and I am the only one, we're the only ones that care about this much and that was a really big thing...taking personal responsibility to make something, to make this better.

Several participants recollected the energy required to ensure the safety of their homes by eradicating potential mold growth:

Our first priority was above and foremost...get everything wet out of the house immediately and that's what we did, so we're flooded in the evening, by the next afternoon-evening, this house was pretty well empty of anything other than maybe like wood furniture, which FEMA had talked to us, Red Cross had talked to us, a lot of different organizations were through...coming and phoning, and a lot of stuff on the news and all that kinda stuff...that you were just kind of saturated with it [clean-up information]. Wood furniture...if you just cleaned it with Clorox, you know...a solution of Clorox and water...it wasn't going to hold anything or breed any mold... or at least that's what they told us, so we took their word for it.

Similarly, another participant took great care and energy to assure the family would be safe upon returning home by the following statement: 
Like I say, most of all I was scared 'cause of mold. Then I used to go outa here, and I'd spit up blood, you know what I mean, because I wanted to make sure it would kill it... 'cause this guy that done the house... he knew about old houses and he told me... "You spray, you spray that Clorox on there. That'll do it just as much as anything.”

Despite the total loss of all possessions, another participant recalled her commitment energy used to help her father clean up his home as evidenced by the following:

I mean, there's nothing you can do to help me... all my stuff; it was gone. I had nothing to clean up. I had nothing to pack away. I had nothing to put in a trash bag. You know, nothing except for the shirt on my back. That's all I had. I was like, you know, "We just gotta help everybody else because there's other people who still have their houses here that need cleaned up." So we worked on my dad's house for a while and my dad got to the point where he wouldn't leave the house. So we would sleep out on the back deck. We got cots from the fire station and we literally slept out on the back porch just me and my dad. We left...my brother just lives in Follansbee so we would go back and forth but at night time, me and my dad, he wanted to stay down there. So I would stay down there with him.

\section{Making deliberate choices about future life decisions in light of the flood experience.}

All participants described experiences associated with the decision-making process when rebuilding their lives and homes. This participant recalled how the flood experience influenced her decision when she purchased a new vehicle after her other one was destroyed by the flood waters:

I remember I had to get a vehicle, and the insurance company I remember they of course totaled my car and pretty much handed me a check right out of the gate, I mean....I mean it was pretty bad (chuckle) and I can remember thinking you know....my husband saying "well, you can have anything you want, I mean what kind of car do you want ..what do you want to do?” The first thing I said was that I do not want a car, I want a SUV, I want to be up off the ground. And...I had never driven an SUV, you know, I'd always had a car, and that was the first thing I did, I went and bought a big SUV so I didn't have to worry about flooding (laughs).

Another participant remembered the influence the flood experience had when determining their next home purchase: 
Yeah, so, you know, at different times we had thought about buying that house that we were flooded in, buying that off of him [brother-in-law]; but then we obviously weren't going to go back to that so we got lucky, we found this [current home]. You know, we rented off, and the lady we rented off of was a real estate agent so, I think we lived there like, eight months. And then she let us out of our lease, 'cause she sold, she got the commission on the house here. Yeah, so we came, you know, 'cause it was in our price range and my husband wanted a little bit of extra yard. So she showed us the house and we looked at it, and it was on a hill, so, I figured it was safe here.

Other participants described their flood experiences as having similar influencing factors

when deciding to rebuild or reorganize their homes as evidenced by the following statement:

It's all about how the water...if it keeps on going, boy, you know... all in all, like I say, it just made me think about no more rugs, no more rugs, man. I mean man, you...God and yeah, but they're so heavy to get out. My God, I never wanna...so we have hardwood floor now. It makes you change, say, "Well, maybe we would like to have got it before but this showed us,” You know what I mean? It makes you think, you know... having something better than what you... all our windows down in the basement they're...Block windows. The guy that had the block windows... their windows wasn't blown out.

Other participants recollected how family members influenced the decision whether to

rebuild or move to another home as stated by this participant:

It was important for them [children] to see...okay...you know... we can do this...it's like rebuilding...you know...it's like building a new house and this is what we're going to do or we can say forget it...this is too much for us. We don't feel we can do it and we can go look for something somewhere else. They [children] were adamant that they were staying in their house....and I mean...they were young... and we wouldn't given them full course of that decision...but had they even shown any inkling of like...it was going to be too much for them, we would of probably just cut our losses and...went somewhere else because we didn't want the stress to be on them 'cause...this was gonna be a lot of work...

Finally, this participant recalled the decision to organize possessions differently in his home in

the event of another flood event as described below:

The majority of stuff in the basement is now up on, I don't know what you call them, but, anything on the floor is no longer on the floor. It's sitting up a good six to eight inches because that way there, I know that the water level won't hit, providing that I'm here to open the door, if there would ever be another water issue in the basement. 


\section{Living an always present uneasiness when there is heavy rainfall. All participants}

expressed significant apprehension and concern when it rained heavily. Two of the participants

admitted to physical symptoms when the rain fell. This participant described her inability to

sleep when it rained in the initial months following the flood:

It could be... dead a night, I could be sound asleep and if I heard one raindrop hit the roof...my eyes would shoot open and I would just sit up and I didn't panic, that it was going to flood, so much as...I would just wake my husband up and go, "Did you hear that?” And he'd be sound asleep, and...you know, now I'm shaking him...” Do you hear that? Did you hear that?" and he would sit up and he'd go, "It's rain." And I'd go, "Yeah...” and he’s like, “Okay.” And I'm like, “It’s rain.” And I almost did it and didn’t realize I was doing it. I knew I was doing it... and I knew, you know...there were no flood warnings, it was just gonna be a normal rain, but I would just lay there and listen to the rain. I don't know what I thought was going to happen or not happen, but that was for a long time.

Another participant described the experience of feeling physically ill when it rained as evidenced by the following:

Because, you know, when it rains, my heart goes... and my stomach gets sick. And I'm scared to death I'm gonna come home and find my house flooded. And there is only two, three things I want out of my house. Three things...I've told everyone. If my house floods, just get three things out. Get my dog, my two cats and my parents bought me this clock.

Several participants described the vigilant watch over the creeks located near their homes

when it rains. One participant recollected how his friends call to inquire about the creek levels near his home as described by the following:

I'd say, all, everything, was, it made me think about, you know, the weather. The weather is very important and like I say, even...even my friends... whenever it was raining and stuff, they'll call me...they'll say, "How is it down there?” [near creek]

Similarly, another participant described monitoring the creek levels for the family when it rains heavily: 
We kinda keep an eye on the creek a little more when it rains. My mom gets worried sometimes and actually they...over by the church, I mean, it's come pretty close recently, just this past fall. A couple big rain storms we got. It was a couple feet from the road, but never really got up...nothing comparable to back in '04. Yeah. Like if it's a rainy night, I'll get up, maybe in the middle of the night or something and just take a peek out the window or walk across the road and just see how high it is. But, I mean, it hasn't even come close to what it was.

Finally, another participant described the need to monitor creek levels despite her new

home not being affected by rising water levels. This is described in the following statement:

Even now when it rains, and we have a creek down below and the creek does have a tendency to overflow, has no impact on our house, but I can see you know the both of us, we're down there looking at it. You know, watching... it was recently it was almost nine o'clock at night and the rain had stopped and my husband and son and I had walked down to the creek and we were watching... and it's bubbling and I'm like... Ah see, see it's never going to go away.

\section{Reflecting on a changed life perspective that surfaces in day to day living. All}

participants concede that being affected by the flooding has changed their life perspectives in a

variety of ways. Two participants reveal changes in their view of material possessions as

described by one participant in the following:

It was kind a funny 'cause the joke was always you know, I always had the fake fingernails and during that time the joke was boy, the fake fingernails came off, and the highlights in the hair came out and she was just, yea... it was because like nothing else mattered. Didn't care about my nails, I don't care about the cars, didn't care about the hair, and all these stupid materialistic things that I had cared about, I was like no...I want my life back. And I think it was kind of funny because that did put it into perspective a little bit, it was like the things that you know... had mattered so much before like nothing in the big picture.

Likewise, other participants described the change in priority for what and how their

money was spent after the flood as evidenced by the following from this participant:

Material-wise, before I used to be just a bitch. I mean, I don't know how else to put it. I wanted \$500 dollar jeans. I'd not think twice if I wanted a \$500 purse, if I wanted it, I 
had it. I went to work. I paid for it. It wasn't like I'd run my credit cards up. If I wanted something, I'd save my money and I bought it. I would never go to Kmart shopping, Wal-Mart shopping. Now I could care less. I wore jeans donated from the church. People I didn’t even know wore them. I always had \$500 Luis Vuitton purses, Coach purses, you know, my nails were always done. They're not done anymore. I had my toes done every week. Haircuts every month. Everything and now, I don't care. I used to really care, like, my make-up, what I looked like. Now, I mean, I was in flood mud for six months, no one looked pretty. I just kind of...not that I don't care about myself, it's just less, I care less about what I attain, financially.

One participant recognized a difference in priorities as well as the inability to control all

situations concerning her family as described below:

I think what it [flood] taught me was...I can't be in control of every situation...because...you know...before I had everything in order...it didn't have to go my way...if someone didn't like it... wanted to change it...that was fine, but I had everything very laid out for how it should be. Now I'm just like...fly by the seat of my pants, and I never thought I would ever be able to say that, especially over the last maybe two or three years. Before I would get so stressed out about it, that I would have like a bad migraine headache because of it...or something... and now...I'm just like...I don't want to say I quit caring...I don't quit caring...I'm just like...Oh, well...okay then...you know...let's think about this other way, and I think that's different for me...that's different for my husband, 'cause he's only known me one way, it's different for my kids... and I think it's an easier way to live. With that being said, you have to care about the important things, but...the small things...don't sweat em, because it can all be, it can be replaced...it can be fixed...it can be, you know...taken care of and yeah...that's...it is....I have to laugh, when I think to myself that...you never know what's gonna to happen. You know...live...live each day, plan your week...but be ready for change. I guess that's it.

The flood experience influenced this participant to want to help others that may be in

need from a similar situation in the future as described in the following:

Well, I think that I'm definitely, like I wanna help people a lot more now. I wanna be the one to kinda save the day sometimes. (laughing) You know, and I think that's 'cause, I mean, really, like the outpouring of generosity from other people really just kinda gave me that outlook, like you know, that in this world there are still good people left. You know, there's like still this is...this is a small valley but there are some wonderful, very 
warm individuals that, you know, would do whatever they can. I was like, "I wanna be more like that.” You know, I wanna help people and I wanna give back to others, and I wanna give what was given to me.

Another participant described going through the flood as a spiritual awakening leading to a changed life perspective as evidenced by the following statement:

Just wanted to get into our home, you know, we had experienced a lot of personal tragedy and things like that prior to that [flood], it was like oh my gosh....here we finally had the chance to kind of become settled and it was like you know...God came in and kind of rattled us up little bit.

Similarly, this participant described the help received from a church group while rebuilding, as help sent from God as evidenced by the following:

And my cousin brought people from his church. They hung all my drywall...in one room. Then the women would finish everything. The guys went to the next room, and they were, they were sent to me by God, 'cause I'll tell you what...I was shocked. He called me; I'm like, "my cousin is coming to drywall tonight.” I thought my cousin was coming. My cousin and his posse came.

Despite the catastrophic losses associated with the flood, many participants describe positive outcomes resulting from their experiences. This participant revealed feelings of being physically and emotionally stronger following the flood as articulated below:

I think that one of the things that I did learn was that I'm a very strong person, and I also am very physically strong and able to do things that I had never in a million years imagined I would be able to do. You know, from tearing out dry wall and whatever, just all these things I would have never imagined myself doing.

Another participant found a sense of accomplishment after playing a major role in rebuilding his home:

You know, so much of a slap in the face and sayin', "Well, what are you gonna do about it?” You know? It makes you just think, 'Well, I gotta do somethin'.” You gotta start 
somewhere. You know, and that...that changed me. At least I done somethin'. You know... But this I did and it was somethin'...I was real proud.

Lastly, this participant acknowledged the flood as a significant influence in the person she has become today and although painful, would not change the situation in any way as described below:

I would not change it...for the world. It has made me a better person. I feel as though it has. I mean, I was very, kinda harsh and, not really materialistic but I was frivolous, you know, I thought that, you know, if you had some designer this or that; you know what I mean?...like it meant something. And, now, my family is with me. I've got my kids, my mom and dad and we all have our health, you know, and God's taking care of us, so that's where I look at it now.

\section{Maintenance of Rigor}

Study rigor and trustworthiness were maintained by careful explanation of each step of the data analysis process keeping in mind the guiding framework of the phenomenological method of inquiry adapted by Giorgi (1985; 1997). To further provide rigor through member check, meaning units and themes were shared with two participants. After reading these pieces, one participant stated "There is nothing I would change here” after reading the serial data with meaning units. Further, this participant found it "amazing" and "right on the money" that the meaning unit and theme portions captured the intent of the story that was shared in August 2009. The second participant's review of the meaning units and themes also substantiated study rigor. When referring to the review of the appropriate data the participant stated "It is very good. It was exactly what I tried to convey.” In addition, the dissertation chairperson guided all phases of the analysis process. Credibility was insured using strict organization of each individual story, meaning unit, transformed language, and theme synthesis for maintenance of an audit trail. 


\section{Summary}

The research question posed for this study was "What is the structure of meaning in the experience of living through a flood situation where there is catastrophic loss?” Using story theory and the phenomenological method of inquiry adapted by Giorgi (Giorgi, 1985) as guiding frameworks, fourteen themes emerged to describe the structure of meaning of a flood event where catastrophic loss had occurred. These themes serve as foundation for illuminating the importance of the study findings by informing the nursing body of knowledge, understanding the transformative influence for each participant, and in the identified implications for nursing research and practice. 


\section{Chapter 5-Discussion}

The purpose of this study was to examine the structure of meaning of living through a flood event where catastrophic loss had occurred. The phenomenological method of inquiry adapted by Giorgi (Giorgi, 1997, 1985) and story theory (M. Smith \& P. Liehr, 2008) were used as guides for data collection, analysis, and discussion of findings. The research question was "What is the structure of meaning in the experience of living through a flood situation where there is catastrophic loss?” As discussed in the previous chapter, fourteen themes were identified constituting the structure of meaning of experiencing a flood event where catastrophic loss had occurred. The purpose of this chapter is to discuss the findings of this study as it relates to story theory, transformation, and existing disaster literature. Implications for nursing knowledge development, research, and practice as it applies to the study findings will be offered.

\section{Story Theory}

The three concepts central to story theory include intentional dialogue, connecting self inrelation, and creating ease (M. J. Smith \& P. Liehr, 2008). These concepts were integrated in the gathering of stories of those who experienced a flood event where catastrophic loss had occurred. Intentional dialogue was established by the rapport with those who chose to share their stories. Further, intentional dialogue was demonstrated by the researcher's undivided and attentive presence with the participants while their stories were shared and in the questions used to gain clarity of the meaning of their experience. 


\section{Intentional Dialogue}

The stories of the participants in this study were deeply held and ready to be told to someone attentively present to listen. As the data collection phase moved forward in this study, the researcher made an important observation about the stories being shared by the participants. All people who chose to participate in this study wanted and most importantly needed to tell their flood stories in spite of the six year time period that had elapsed since their experiences. Telling and retelling the story allows the storyteller to continue to make meaning of their experience and release emotions (Kaminer, 2006). This was expressed in the vivid detail and deep emotion in which each story was shared.

The way in which these stories were told, illuminates the ongoing process of resolving the catastrophic flood event by retelling or recounting. This allows for a perspective that evolves over time and enables the healing process to continue (Mashiach, et al., 2004). The stories in this study moved from the day of the flood event, through the rebuilding process, to finally a retrospective view of self before the flood event to the present time. As these stories were told, it was apparent that the healing was an on-going progression during the six year period following the flood. This was evident through the recognizing and acknowledging the changes in perspective regarding self and world since the flood occurred.

Participants shared photos and newspaper articles about the flood and were willing to open their homes to the researcher so they could recount visually the devastation that occurred to their residence and property. This personal sharing not only provided insight for the participant, but assisted in building a mutual respect between the researcher and the participant. It is the co- 
understanding of one's story by another human being that provides the power for healing (Hovey \& Paul, 2007). With this emotional telling of the story, each participant was afforded the opportunity to heal by finding new meanings in their previous experiences, and transformation of self represented by changes in life perspective and life purpose.

\section{Connecting with Self-in-Relation}

Connecting with self-in-relation encompasses self-awareness within the moment relative to the unfolding story plot (M. J. Smith \& P. Liehr, 2008). Plot is a dimension of story theory that depicts the qualities of connecting with self-in-relation for the person. The theme is an outcome of the analysis of the structure of meaning of the lived experience. Plot and theme come together as the two are integrated in deriving conclusions for the study. The story plot which is the unfolding story qualities include: facing the devastation, embracing the rebuilding and developing inner strength.

Facing the devastation. Several themes represent this facet of the story plot of facing the devastation. The first three themes of "beginning as the usual everyday despite heavy rainfall”, “increasing recognition of rising flood waters as communicated by flood warnings via family, friends and airwaves", and "growing apprehension when faced with rising flood waters and the likelihood of damage yet to come” were evident in all stories collected. Each story offered in this study described the experience of hearing about the impending flood and watching the devastating ravage caused by the quickly rising flood waters on a day that began as normal. The sights and sounds evolving within minutes, left participants with feelings of disbelief and amazement. 
The fourth theme of "shifting to concentrate on what needs to be done to secure possessions and the safety of pets in the midst of the rising flood waters" was observed as the participants discussed their experiences of being in the midst of unsafe and potentially dangerous circumstances when trying to secure the safety of their pets, homes, and properties. With no choice except to flee from the area as they witnessed the unfolding devastation, all participants described significant levels of confusion, uncertainty, and fear as they anxiously awaited the opportunity to return home. This aspect of the story plot is represented by the fifth theme of "watching the power and destruction of the rising flood waters in agonizing disbelief".

All stories reflected the commonality of finding comfort in the respite of others' homes while the chaos of the flood event persisted and is reflected through the sixth theme of "retreating in haste from the danger of the rising flood waters to the safe reprieve of higher ground and relatives' homes”. This part of the story plot offers the opportunity for each participant to reflect and share experiences that facilitate a connection with oneself and humanity (Sierpina, Kreitzer, MacKenzie, \& Sierpina, 2007). The full scope of the devastation was later described by all in an attempt to recognize the meaning of the situation.

In the following days after the flood, the level of loss was beginning to solidify as the stories unfolded. This aspect of the story plot is reflected in the seventh and eighth themes identified as "seeing yet not believing the chaos and expansive devastation when returning home" and "coming to know the breadth of destruction and substantial ruination of belongings and property” respectively. Although losses varied among participants, all described feelings of being overwhelmed and confused. In the midst of the ruination, many told of the emotional struggle to understand the devastation that occurred and to make sense of their situation. This 
aspect of the emerging story plot is critical as the meaning-making process is essential for the healing to occur (Etherington, 2009; Gladding \& Wallace, 2010). As time passed, the enormity of the massive rebuilding efforts began to clarify.

Embracing the rebuilding. In this phase of the story plot, the ninth theme identified as "contemplating the overwhelming task to restructure life and home to what once was" is illuminated. All of the people who chose to participate in this study described the laborious task of rebuilding their homes and lives. The clean-up efforts required great emotional and physical exertion as described in detail of how each participant moved through this endeavor. Cherished heirlooms, family pictures, and in two instances entire homes were destroyed as each participant talked of the trauma associated with the catastrophic loss of their possessions. This talk of the trauma within the emerging story plot was important for validation of the participant's story since this enabled the participant to have a continuing forum for communicating their experiences in a coherent manner (Hall, 2011).

Each story described the concern and determination necessary to ensure the safety of the participants, their families, pets, and in the eradication of mold as the rebuilding continued. Energy and commitment were required for weeks and months to rebuild as the participants attempted to regain a sense of normalcy for themselves and their families. All participants described feelings of gratefulness as the outpouring of help came while they picked up the pieces of their once familiar lives and is evidenced by the tenth theme of "overwhelming heartfelt gratitude for the assistance of others to reestablish home and property destroyed by the flood waters". As the stories continued to unfold, participants described the challenges associated with the physical labor, emotional strain, and decision-making processes involved in rebuilding or 
relocating to another home as evidenced by the eleventh and twelfth themes identified as "taking on the effort to rebuild with energy and commitment" and "making deliberate choices about future life decisions in light of the flood experience.”

Participants recollected a sense of pride and accomplishment after playing an integral role in the reestablishment of their homes. This phase of story plot served as an important channel for individual learning and recovery (Eyre, 2009). As the story sharing progressed, all participants reflected upon the change in perspective regarding the sense of self and view of the world resulting from the flood event.

Developing an inner strength. All participants acknowledged the presence of concern and in some instances physical and emotional uneasiness when significant rainfall persists. Participants told of the inability to sleep or relax when the rain begins regardless of the issuance of flood warnings. Those who chose to rebuild and stay in the same home as before the flood reflected about the need to monitor nearby creek levels frequently when it rains heavily. This aspect of the story plot is represented in the thirteenth theme of "living an always present uneasiness when there is heavy rainfall” and represents the continued development of inner strength and perspective as evidenced within the unfolding story plot.

All participants described the evolving changes in personal perspective that took place since experiencing the catastrophic loss from flood. A significant change in one’s perspective often occurs following a traumatic or other life-altering event and involves an alteration in one's core assumptions about the nature of things (Mandala-Schlitz, Vieten, \& Amorok, 2007). Many recognized both stronger internal and external resilience and an altered perspective in relation to 
life priorities as they continued to make meaning of their flood experiences. Openly sharing personal stories may assist those recovering from trauma to become both mentally and physically stronger and offer the opportunity to look to the future with possibility and hope (Gladding \& Wallace, 2010). This potential influence on healing is essential for nurses to understand so they can better assist those who have experienced catastrophic loss from flood and other natural disasters.

All participants recognized the shift in attitude regarding life priorities and in preparing for future flood situations that may arise. Stories reflected a connection between the flood and spiritual awakenings. Participants described a deep connection between their flood experiences and as a possible sign from God. These participants expressed a clear reason as to why this trauma happened resulting in an increase in physical and emotional strength. This is important since religious reflections of faith can affirm the meaning of suffering and in maintaining their transformed lives (Adeney-Risakotta, 2009; Zahourek, 2007). These reflections facilitate a deeper understanding in the meaning of one’s personal story lending to a change in life perspective. (Bunkers, 2006; Etherington, 2009).These changes were recognized as positive and considered an important piece of the healing process and support the fourteenth and final theme of "reflecting on a changed life perspective that surfaces in the everyday." These descriptors of the story plot comprise the knowledge continuum of the health experience for those who suffered catastrophic loss from flood. 


\section{Creating Ease}

The concept of creating ease is the unity of important story moments to facilitate comprehension and movement toward resolving the health challenge being explored (M. Smith \& P. Liehr, 2008). This was evidenced through witnessing each participant's emotion as they willingly and without reservation shared their stories with the researcher. Raw emotions were evident in the stories as evidenced through crying and significant inflection in voice tone as they told about their experiences. As many participants talked, episodes of laughter were interjected throughout their stories. These episodes may have been exhibited for a variety of reasons including initial uneasiness when speaking of their experiences, increased comfort in talking with the researcher as the story unfolded, and a fond recollection of a specific time during the rebuilding process described within the story. After sharing their stories, many participants demonstrated a sense of gratitude for the opportunity to have the researcher attentively listen to them. Many participants expressed hope by sharing their stories that they may help others who experience a similar circumstance in the future. Their hope and gratitude may be an influence in further validating their stories leading to continued resolution of the emotional challenges associated with the flood experience.

Attentively listening to each thread of a participant's story provided the researcher a rich opportunity to witness the making of a beautiful tapestry by validating thoughts and feelings within the story plot. Through thoughtful and focused reflection, the storyteller's suffering may be recognized through being witness to the emerging story plot (Rosenthal, 2003). It was this process that captured the essence between the person telling the story and those unconditionally wanting to listen, an underlying premise of story theory (Liehr \& Smith, 2007). 
The stories gathered from the participants in this study, involved the personal experiences with massive flooding that occurred as a result of Hurricane Ivan in September, 2004. Despite the flood occurring over six years ago, the participants demonstrated significant abilities to recollect their experiences with vivid and detailed descriptions. All of the stories collected were told with emotion and moved from the typical beginning day, through the description of witnessing the devastation and completing the rebuilding process, and finally to the reflections of personal transformation that transpired as a result of the flood.

The healing potential of telling one's story continues to gain attention in the healthrelated literature, however more work is needed (Bunkers, 2006; Gladding \& Wallace, 2010). As the psychosocial realm of practice remains immersed in recognizing the benefits of sharing personal stories following a traumatic life event, the nursing discipline is making strides in this area of inquiry, potentially adding new knowledge to the nursing discipline (Bunkers, 2006). As the story gathering process unfolded, it was apparent that the people who chose to participate in this study wanted and needed to share their stories. This was evidenced by the willingness to tell their stories in great depth and at times with raw emotion as if they were reliving the flood once again.

\section{Transformation}

A definition of transformation gleaned from the findings of this study is a change in perspective that brings about a deeper understanding of one's life purpose. This transformation is evidenced through several themes identified within the study findings. In regard to the structure of meaning of the lived experience of a flood event where catastrophic loss occurred, the 
transformational process has evolved over time and is reflected through changing views in life perspective and purpose.

\section{Changing Perspective}

Transformational views of self, world, and life perspective often occur after a traumatic experience such as catastrophic loss from flood (Bunkers, 2006; Etherington, 2009; Gladding \& Wallace, 2010; Rateau, 2010). Self transformation involves a profound change in consciousness that results in a long-lasting alteration in worldview, through relationships with oneself, others, culture, nature, and the divine (Mandala-Schlitz, et al., 2007). This transformational shift possesses a growth quality, moving beyond one’s existence prior to the catastrophic event. Findings from this study support these transformational views regarding life perspective and purpose. These views are forever integrated in each participant's life and validated through the stories told in this study.

Personal transformation and recovery may come with the re-telling of one’s story (Hall, 2011). As all participants retold their stories, the continued opportunity was provided for discovery and validation of transformation of self. This transformative process takes place through thoughts, feelings, and values that result in a person's changed perspective of the whole. This perspective is fostered through a mutual and creative unfolding of one's story within the human health experience and is strongly evidenced by the fourteenth theme of "reflecting on a changed life perspective that surfaces in the everyday”.

Participants sharing their stories spoke freely of their transformation regarding what was most important to them following their flood experiences. Participants described the differences 
in attitude regarding the purchase and ownership of material goods. Participants acknowledged the necessity for wanting or needing expensive items or services held less importance following the flood. The manner in which the participants valued these possessions or services significantly diminished, as described in their stories. When discussing their losses, participants talked of the emotional distress associated with the loss of belongings that held sentimental value, regardless of monetary worth.

As the acquisition of material possessions became less of a priority, participants recognized the importance of the relationships initiated, maintained, and strengthened as a result of their flood experiences. All participant stories were integrated with recount of the participants' appreciation of families, friends, and pets. Deeply intertwined within all stories were the importance of loved ones, sense of teamwork, and extreme pride and resilience. The latter qualities reflect the eleventh theme of "taking on the effort to rebuild with energy and commitment”. Recognizing and acknowledging the meaning of such qualities may be a source of strength and positive growth (Kaminer, 2006).

Equally prevalent was the feeling of gratitude expressed for the physical and emotional support received during and after the rebuilding process. Participants described the emotional impact related to the outpouring of assistance offered during the flood. All stories described the abundance of help that was given during the initial weeks and in several instances months after the flood. This evidence of transformation is represented within the tenth theme of “overwhelming heartfelt gratitude for the assistance of others to reestablish home and property destroyed by the flood waters”. 


\section{Changing Life Purpose}

As are result of the outpouring of help provided, several participants described the strong desire to give back to others and their communities as a result of their personal flood experiences. Post-traumatic resilience and the continuation of self-transformation may be channeled through the use of one' own traumatic experience to readily assist others in need (Etherington, 2009). Transformation as it relates life perspective may be experienced through creating work or doing a deed that moves one beyond self. Self-transcendence emerges when one reaches beyond personal awareness to consider the best interest of another, even in the most difficult circumstances. This aspect of transformation is associated with the fourteenth theme of "reflecting on a changed life perspective that surfaces in the everyday".

Participants described changed insight regarding the fragility of life and the importance of living in the present time, which supports the fourteenth theme of "reflecting on a changed perspective that surfaces in the everyday". Unfolding stories reflected an understanding of how any life situation could be changed in seconds with little or no warning. Embedded within participant stories were feelings of vulnerability and uncertainty regarding control of every facet of daily life. Participants recognized that all aspects of living couldn’t be controlled or manipulated regardless of the commitment or energy to do so.

Participants told of their personal transformations regarding life purpose and in the ability to relent control of issues they now deemed less important. Flexibility in completing everyday tasks and recognizing the importance of keeping time for loved ones were strongly embedded in all participant stories. Unexpected traumatic or catastrophic events in particular, prompt 
individuals to evaluate the order and purpose of life as a whole (King, 2004). This feature of transformation aligns with the fourteenth theme of "reflecting on a changed life perspective that surfaces in the everyday”.

All participant stories reflected affirmation in the flood event being a terrible and lifealtering experience. Despite the initial negative impact, those who chose to participate in this study reflected on the positivity of their flood experiences. Although participants acknowledged they never want to go through a similar event, belief that the flood served as a catalyst for personal growth was evident. Participants acknowledged that the flood experience facilitated the transformational process of becoming a better person and that clearer sense of life purpose emerged, allowing for clarity for what is most important to the person who has experienced the event. Sharing positive aspects of a traumatic story assist in building a more rewarding sense of identity and self (Etherington, 2009). These pieces of the evolving story support the theme of "reflecting on a changed life perspective that surfaces in the everyday".

All of the stories reflected a change or transformation in thoughts regarding the powerful impact of weather, particularly rain on the participant's life. The emotional impact of another flood event remains with all the participants at present and is profoundly evident in each story gathered. Participants described feelings of both physical and mental uneasiness when rain would begin to fall even in the absence of flood watches or warnings. Participants conceded the need to monitor creek levels located near their homes when it rained held a different purpose and meaning after the flood. Through their stories, all participants acknowledged the intense power of the flood-producing waters, and recognize the need for action in a moment's notice. These 
aspects of the unfolding stories align with thirteenth theme of "living in always present uneasiness when there is heavy rain fall”.

Further, the twelfth theme, "making deliberate choices about future life decisions in light of the flood experience” was reflected in the evolving stories told by participants. All participants talked about the decisions that were made regarding the rebuilding and organization of their homes and properties, keeping in mind the possibility of another flood in the future. Participants acknowledged that decisions to rebuild, relocate, and purchase items lost were heavily influenced by their flood experiences and were reflective in their stories.

A majority of the participants resolved to stay in their homes that were damaged and in need of repairs, however two participants found the potential of another flood event too difficult to imagine and therefore relocated to other areas. The participants who chose to rebuild and remain in their residences located near small creeks or streams recollect the necessity to monitor the water levels when prolonged rains occur. Although some of these activities have subsided over time, participant stories demonstrate that this aspect of transformation remains a significant influence in the participants' lives. This sustaining facet is reflected in the thirteenth theme of "living in an always present uneasiness when there is heavy rainfall".

\section{Research Findings and the Literature}

There are several studies within the literature that relate to the findings of this study that warrant discussion. Multiple studies have found increased negative psychological effects associated with the loss of material possessions after natural disaster (Caldera, et al., 2001; Chou, et al., 2004; Suar, et al., 2002). This study explored the lived of experience of a flood event 
where catastrophic loss had occurred. The findings in this study emerged from the stories that were told from the participants' perspectives and moved beyond identification of negative psychological effects that occur after a flood disaster.

While these related studies provide foundational support in identifying the types of psychological symptoms and coping strategies demonstrated by disaster survivors, they do not reflect the structure of meaning of living through a flood event from the survivor's long-term perspective. This study adds to the existing body of knowledge by illuminating the entire story from the beginning of the flood to the present time allowing for each participant to validate their experience. The context, in which the story was told, may have influence in the healing process after a six-year time period. Further inquiry is critical in understanding the influence of time and healing following catastrophic loss from flood.

Findings from a qualitative study exploring the immediate lived experience of 2004 tsunami survivors identified the themes "changed understanding of life" and "power of communion” from data collected twenty-one months after the disaster (Raholm, et al., 2008). Although several related themes were identified in this study's findings, participant stories were gathered after longer time period following the flood disaster. The supporting themes of "seeking meaning" and "seeking support" were identified in a separate qualitative study examining coping strategies in three separate groups of people who had experienced natural and man-made disasters (Ibanez, et al., 2004). Stories from this study reflected two themes that relate to "seeking meaning". The eighth and ninth themes of "coming to know of the breadth of destruction and substantial ruination of belongings and property" and "contemplating the 
overwhelming task to restructure life and home to what once was” were evident in all participant stories and inherent in the reflection of life purpose a purpose as the rebuilding process ensued.

Embedded within all stories was the participant's recognition of the ongoing struggle to make sense of the flood experience. This was strongly evident while participants returned home to find massive devastation to their homes and properties and in the overwhelming task of rebuilding their lives. Further, the findings from this study provide the opportunity to better understand past and present meanings of the flood experience and the transformation of self which has evolved since the flood event. These findings may contribute to the existing body of knowledge by explicating specific exemplars of self transformation.

\section{Implications for Nursing Knowledge Development, Research, and Practice}

The study findings hold significant implications for nursing knowledge development, research, and practice. In exploring the structure of meaning of a flood event where catastrophic loss had occurred, the information obtained as a result of this study may be particularly important for application in disaster-relief, public and mental health arenas. Further, work to better understand the significance of story and its research implications will be discussed.

\section{Implications for Nursing Knowledge Development}

The neomodernist framework discussed by Reed (1995), serves as a significant contributor in the continued quest to expand nursing knowledge. The belief that nursing knowledge continues to evolve from both modern and post modern influences allows for a broadened knowledge base that encourages many sources to contribute to new knowledge. Furthermore, Newman (1991) contends that the focus of the discipline is caring in the human 
health experience. Within the health and human experience, the participant's inner reality of the flood experience was exemplified through the recognition of significant patterns in the unfolding story plot incorporating the study findings.

The findings of this study contribute to nursing knowledge by offering a description of the plot concepts depicting the experience of living through a catastrophic flood event. These findings are associated with the developmental-contextual worldview within the described metanarrative by Reed (Reed, 1995). The people who chose to participate in this study shared stories of a life altering, historical event they experienced. The devastating flood and associated catastrophic loss were catalysts for tremendous chaos, confusion and ultimately a changed life perspective for study participants. This evidence is in keeping with developmental-contextual worldview in that chaos and conflict often provide energy for ongoing change in an individual with the patterns of change rooted in a dynamic context (Reed, 1995).

\section{Implications for Nursing Research}

To further support the findings of this study, it is important to consider the investigation of persons who face catastrophic loss from flood. Those who chose to participate in this study were eager to share their stories from the flood event that occurred over six years ago. In spite of the significant time lapse between the actual flood experience and the gathering of stories for this study, participants shared their stores with great detail and emotion. Inquiry regarding length of time following catastrophic loss and long-term physical and/or mental health effects associated with such loss is warranted. 
The study findings support the need for further inquiry involving other natural or manmade disasters. Further, studies over a longitudinal time period in other geographical areas may be beneficial in understanding the transformational process that evolves over time with people affected by catastrophic loss. While literature supports the stabilization of mental health effects within six months of disaster, more work is needed for longitudinal studies involving disaster research (Benight \& McFarlane, 2007). It remains unclear what personal transformations regarding changing life purpose and life perspective occur long after the mental health effects have subsided. Further, qualitative inquiry methods using stories to explore these transformational processes are not prevalent in the existing literature. The researcher plans to continue to work in this area of inquiry to further contribute to the nursing body of knowledge using story theory and a phenomenological method of inquiry as frameworks for future studies, for example, other disasters over different time periods.

Through the study of the lived experience in persons who have experienced catastrophic loss from flood, the study findings may be applied in uncovering unexplored knowledge of such events. The findings of this study clearly support that living through a flood event where catastrophic loss had occurred was a life-altering event in each participant's life. The changes in personal perspectives and life purpose were acknowledged by the participants in their stories. Questions remain in regard to uncovering such transformations, why they occurred, and the evolution of how the survivor of natural disaster comes to recognize the presence of personal transformation over time.

Further, investigation relating to the impact of story is needed to better appreciate the connection between the healing process and storytelling. A pre-test, post-test inquiry following a 
disaster whereby one group would engage in telling their story and a second group would not tell their story may assist in further understanding this connection between healing and story. This investigation should consider the meaning of the disaster event in both short-term and long-term circumstances so the full impact of the event can be recognized by the nurse. Variables such as well-being, quality of life, and life purpose could be gathered in the pre-test, post-test phase of the study may provide clarity regarding what is most important to the survivor experiencing catastrophic loss from disaster.

\section{Implications for Nursing Practice}

The findings from this study may hold significant implications for nursing practice, particularly in community, disaster-relief, and mental health areas. An important aspect evolving from this study was the relationship between the emotions and detail in which the story was shared and the length of time since the participants experienced the flood event. While literature supports the plethora of aid given to those experiencing catastrophic loss immediately after disaster, mental health nurses must become more cognizant of the potential long-term needs of those affected. Providing assistance and appropriate support in order to maintain a healthy recovery may be accomplished by careful assessment of the person’s accompanying story (Wysoker, 2006). Through this increased awareness from not only short-term assessment, but with long-term assessment, nurses can be better informed to create and implement interventions for the long-term survivor of catastrophic loss from natural disaster.

Exploring the power of story when conducting assessments in practice for those who have experienced catastrophic loss from natural disaster may facilitate recovery. When providing 
appropriate care and support, nurses assist in the rebuilding of lives following catastrophic loss. Stories shared between nurse and client is both a powerful and integral channel for remolding one's life perspective (Bunkers, 2006). It is more important than ever to consider the approach in which nurses interact with the person telling the story and how critical this piece of the nursing assessment is during pivotal times in the recovery process, since telling the story may increase awareness of what is really important to the person who experienced the catastrophic life event. In doing this, nurses may better assist the person to understand their potential and life purpose (Gaydos, 2005; Sierpina, et al., 2007). More work is necessary in giving one’s story greater currency in a healthy recovery and transformation of self (Frank, 2000).

The stories shared by the participants were told with great emotion and detail regardless of the six-year time period which elapsed following the flood event in September, 2004. Participants recounted their stories freely in the researcher's presence and appreciated the opportunity to talk about their flood experiences as evidenced by their acknowledgement and appreciation to share their story with someone listening in true presence. Although the overall healing power of story was not a focus of this study, the possibilities of using story as an intervention for those affected by catastrophic loss from disaster should be considered. Gathering stories in practice could add another dimension to which nursing care is currently provided to survivors of natural disaster. Gathering stories over time while providing care for those affected by catastrophic loss may be realigned to better anticipate the needs of the survivor and facilitate the healing process.

Findings of this study support the desire to help others who face similar adversities from flood and other disasters. Participants acknowledged the strong influence the outpouring of help 
from friends, family and strangers had on their desires to give back to others in need. This desire to reach out to others may be a key factor when providing care to survivors who experience catastrophic loss. Nurses can offer a bridge between the survivor who wants to help and the variety of resources available that provide volunteering opportunities. Offering this support as a practice implication, specifically in the longer term can provide the survivor affected by catastrophic loss from disaster an important means for continued recovery and a positive transformation of self.

\section{Summary}

The exploration of the structure of meaning of a flood event where catastrophic loss had occurred may have important implications for nursing knowledge development, research and practice. Participants in this study voiced their experiences and perspectives. This voice may be critical for a continued healthy recovery and transforming life perspective following catastrophic loss from flood. 


\section{References}

Adams, R., \& Boscarino, J. (2005). Differences in mental health outcomes among Whites, African Americans, and Hispanics following a community disaster. Psychiatry: Interpersonal and Biological Processes, 68(3), 250-265.

Adams, V., Hattum, T., \& English, D. (2009). Chronic disaster syndrome: Displacement, disaster capitalism, and the eviction of the poor from New Orleans. American Ethnologist, 36(4), 615-636. doi: 10.1111/j.1548-1425.2009.01199.x

Adeney-Risakotta, B. (2009). Is there meaning in natural disasters? Construction of culture, religion and science. Exchange, 38, 226-243. doi: 10.1163/157254309X44971

Ahern, K. (1999). Ten tips for reflexive bracketing. Qualitative Health Research, 9(3), 407-411.

Akerlind, G. (2005). Variation and commonality in phenomenographic research methods. Higher Education Research \& Development, 24(4), 321-334. doi: 10.1080/07294360500284672

Bailey, P. (1997). Finding your way around qualitative methods in nursing research. Journal of Advanced Nursing, 25, 18-22.

Benight, C., \& Harper, M. (2002). Coping self-efficacy perceptions as a mediator between acute stress response and long-term distress following natural disasters. Journal of Traumatic Stress, 15(3), 177-186.

Benight, C., \& McFarlane, A. (2007). Challenges for disaster research: Recommendations for planning and implementing disaster mental health studies. Journal of Loss and Trauma, 12, 419-434. doi: 10.1080/15325020701285128 
Bodvarsdottir, I., \& Elklit, A. (2004). Psychological reactions in Icelandic earthquake survivors. Scandinavian Journal of Psychology, 45(1), 3-13. doi: 10.1111/j.14679450.2004.00373.x;

Bradbury-Jones, C., Irvine, F., \& Sambrook, S. (2010). Phenomenology and participant feedback: Convention or contention. Nurse Researcher, 17(2), 25-33.

Briere, J., \& Elliott, D. (2000). Prevalence, characteristics, and long-term sequelae in natural disaster exposure in the general population. Journal of Traumatic Stress, 13(4), 661-679.

Bunkers, S. (2006). What stories and fables can teach us. Nursing Science Quarterly, 19(2), 104107. doi: $10.1177 / 0894318406286580$

Burley, D., Jenkins, P., Laska, S., \& Davis, T. (2007). Place attachment and environmental change in coastal Louisiana. Organization \& Environment, 20(3), 347-366. doi: $10.1177 / 1086026607305739$

Caldera, T., Palma, L., Penayo, U., \& Kullgren, G. (2001). Psychological impact of hurricane Mitch in Nicaragua in a one-year perspective. Social Psychiatry and Psychiatric Epidemiology, 36(3), 108-114.

Chou, F., Chou, P., Lin, C., Tom, T., Su, P., Ou-Yang, W., et al. (2004). The relationship between quality of life and psychiatric impairment for a Taiwanese community postearthquake. Quality of Life Research, 13, 1089-1097.

Connelly, L. (2010). What is phenomenology? MEDSURG Nursing, 19(2), 127-128.

de Witt, L., \& Ploeg, J. (2006). Critical appraisal of rigour in interpretive phenomenological nursing. Journal of Advanced Nursing, 55(2), 215-229. doi: 10.1111/j.13652648.2006.03898.x 
Etherington, K. (2009). Life story research: A relevant methodology for counsellors and psychotherapists. Counselling and Psychotherapy Research, 9(4), 225-233.

Exline, J., Smythe, J., Gregory, J., Hockemeyer, J., \&, \& Tulloch, H. (2005). Religious framing by individuals with ptsd when writing about traumatic experiences. The International Journal for the Psychology of Religion 15(1), 17-33. doi: 10.1207/s15327582ijpr1501_2j

Eyre, A. (2009). Public mental health case study: Learning (and teaching) from personal experience. Journal of Public Mental Health, 8(3), 28-32.

Flood, A. (2010). Understanding phenomenology. Nurse Researcher, 17(2), 7-15.

Frank, A. (2000). The standpoint of storyteller. Qualitative Health Research, 10(3), 354-365.

Gaydos, H. (2005). Understanding personal narratives: An approach to practice. Journal of Advanced Nursing, 49(3), 254-259.

Giorgi, A. (1997). The theory, practice, and evaluation of the phenomenological method as a qualitative research procedure. Journal of Phenomenological Psychology, 28(2), 235261.

Giorgi, A. (2005). The phenomenological movement and research in the human sciences. Nursing Science Quarterly, 18(1), 75-82. doi: 10.1177/0894318404272112

Giorgi, A. (Ed.). (1985). Phenomenology and Psychological Research. Pittsburgh: Duquesne University Press.

Gladding, S., \& Wallace, M. (2010). The potency and power of counseling stories. Journal of Creativity in Mental Health, 5, 15-24. doi: 10.1080/15401381003640569 
Graneheim, U., \& Lundman, B. (2004). Qualitative content analysis in nursing research:

Concepts, procedures, and measures to achieve trustworthiness. Nurse Education Today, 24, 105-112. doi: 10.1016/j.nedt.2003.10.001

Hall, J. (2011). Narrative methods in a study of trauma recovery. Qualitative Health Research, 21(1), 3-13. doi: 10.1177/1049732310377181

Hamill, C., \& Sinclair, H. (2010). Bracketing-practical considerations in Husserlian phenomenological research. Nurse Researcher, 17(2), 16-24.

Hovey, R., \& Paul, J. (2007). Healing, the patient narrative-story and the medical practitioner: A relationship to enhance care for the chronically ill patient. International Journal of Qualitative Methods, 53-66.

Hughes, F., Grigg, M., Fritsch, K., \& Calder, S. (2007). Psychosocial response in emergency situations-the nurse's role. International Nursing Review, 54(1), 19-27.

Ibanez, G., Buck, C., Khatchikian, N., \& Norris, F. (2004). Qualitative analysis of coping strategies among Mexican disaster survivors. Anxiety, Stress, and Coping, 17(1), 69-85. doi: 10.1080/10615800310001639628

Jones, R., Ribbe, D., Cunningham, P., Weddle, J., \& Langley, A. (2002). Psychological impact of fire disaster on children and their parents. [research]. Behavior Modification, 26(2), 163-186.

Kaminer, D. (2006). Healing processes in trauma narratives: A review. South African Journal of Psychology, 36(3), 481-499.

Kessler, R., Galea, S., Jones, R., \& Parker, H. . (2006). Mental illness and suicidality after hurricane Katrina. Bulletin of the World Health Organization, 84(12), 930-939. 
Kim, S., Plumb, R., Gredig, Q., Rankin, L., \& Taylor, B. (2008). Medium-term post-Katrina sequelae among New Orleans residents: Predictors of poor mental and physical health. Journal of Clinical Nursing, 17, 2335-2342. doi: 10.1111/j.1365-2702.2008.02317.x

King, G. (2004). The meaning of life experiences: Application of a meta-model to rehabilitation sciences and services. American Journal of Orthopsychiatry, 74(1), 72-88. doi: 10.1037/0002-9432.74.1.72

Kleiman, S. (2004). Phenomenology: To wonder and search for meanings. Nurse Researcher, 11(4), 7-19.

Koivisto, K., Janhonen, S., \& Vaisanen, L. (2002). Applying a phenomenological method of analysis derived from Giorgi to a psychiatric study. Journal of Advanced Nursing, 39(3), 258-265.

Liehr, P., \& Smith, M. (2007). Story Inquiry: A method for research. Archives of Psychiatric Nursing, 21(2), 120-121. doi: 10.1016/j.apnu.2006.12.005

Mandala-Schlitz, M., Vieten, C., \& Amorok, T. (2007). Living Deeply: The art and science of transformation in everyday life. Oakland: New Harbinger.

Marshall, M. (1996). Sampling for qualitative research. Family Practice, 13(6), 522-525.

Mashiach, R., Freedman, S., Bargai, N., Boker, R., Hadar, H., \& Shaley, A. (2004). Coping with trauma: Narrative and cognitive perspectives. Psychiatry, 67(3), 280-293.

McBrien, B. (2008). Evidenced-based care: Enhancing the rigour of a qualitative study. British Journal of Nursing, 17(20), 1286-1289. 
McConnell-Henry, T., Chapman, Y., \& Francis, K. (2009). Husserl and Heidegger: Exploring the disparity. International Journal of Nursing Practice, 15, 7-15. doi: 10.1111/j.1440172X.2008.01724.X

Popp, A. (2006). The effects of natural disaster on long run growth. Major Themes in Economics, spring, 61-82.

Raholm, M., Arman, M., \& Rehnsfeldt, A. (2008). The immediate lived experience of the 2004 tsunami disaster by Swedish tourists. Journal of Advanced Nursing, 63(6), 597-606. doi: 10.1111/j.1365-2648.2008.04734.x

Rateau, M. (2009). Differences in emotional well-being of hurricane survivors: A secondary analysis of the ABC news hurricane Katrina anniversary poll. Archives of Psychiatric Nursing, 23(3), 269-271. doi: 10.1016/j.apnu.2009.02.001

Rateau, M. (2010). A story of transformation following catastrophic loss. Archives of Psychiatric Nursing, 24(4), 260-265. doi: 10.1016/j.apnu.2009.09.001

Reed, P. (1995). A treatise on nursing knowledge development for the 21st century: Beyond postmodernism. Advances in Nursing Science, 17(3), 70-84.

Robinson-Wolf, Z. (2003). Exploring the audit trail for qualitative investigations. Nurse Educator, 28(4), 175-178.

Rosenthal, G. (2003). The healing effects of storytelling: On the conditions of curative storytelling in the context of research and counseling. Qualitative Inquiry, 9(6), 915-933.

Sierpina, V., Kreitzer, M., MacKenzie, E., \& Sierpina, M. (2007). Regaining our humanity through story. EXPLORE, 3(6), 626-632. 
Smith, M., \& Liehr, P. (1999). Attentively embracing story: A middle-range theory with practice and research implications. Scholarly Inquiry for Nursing Practice: An International Journal, 13(3), 187-210.

Smith, M., \& Liehr, P. (2005). Story theory: Advancing nursing practice scholarship. Holistic Nursing Practice, 19(6), 272-276.

Smith, M., \& Liehr, P. (Eds.). (2008). Middle range theory for nursing. (2 ${ }^{\text {nd }}$ ed.).New York: Springer Publishing.

Suar, D., Mandal, M., \& Khuntia, R. (2002). Supercyclone in Orissa: An assessment of psychological status of survivors. Journal of Traumatic Stress, 15(4), 313-319.

Tapsell, S., \& Tunstall, S. (2008). "I wish I'd never heard of Banbury": The relationship between 'place' and the health impacts from flooding. Health \& Place, 14, 133-154. doi: 10.1016/j.healthplace.2007.05.006

van Manen, M. (1997). Researching lived experience: Human science for an action-sensitive pedagogy (2nd ed.). Ontario: The Althouse Press.

Wysoker, A. (2006). Psychiatric-mental health nurses and the aftermath of hurricane Katrina: Fulfilling ethical responsibilities. Journal of the American Psychiatric Nurses Association, 11(6), 364-365. doi: 10.1177/1078390305284658

Yoon, I. (2009). A mixed-method study of Princeville's rebuilding from flood in 1999: Lessons on the importance of invisible community assets. Social Work, 54(1), 19-28.

Zahourek, R. (2007). Finding holism in disaster: A story of Katrina's aftermath. Journal of Holistic Nursing, 25(1), 52-57. 
APPENDIX A

IRB Approval 


\section{WWestVurginiaUniversity.}

Office of Research Compliance

\section{IRB Protocol-Exemption}

To: $\quad$ Smith, Mary

From: $\quad$ WVU Office of Research Compliance

Date: $\quad$ Wednesday, November 03, 2010

Subject: Exemption Acknowledgement

Tracking \#: H-22814

Title: $\quad$ The lived experience: Stories from those who have experienced catastrophic loss from flood

The above-referenced study was reviewed by the West Virginia University Institutional Review Board (IRB) and was granted exemption in accordance with 45 CFR 46.101(2).

This protocol was reviewed using the following:

Exemption Checklist (210r)

This research study was granted an exemption because the Research involves educational tests, survey procedures, interview procedures or observation of public behavior and (i) information obtained is recorded in such a manner that human subjects cannot be identified, directly or through identifiers linked to the subjects; and (ii) any disclosure of the human subjects' responses outside the research could not reasonably place the subjects at risk of criminal or civil liability or be damaging to the subjects' financial standing, employability, or reputation [45 CFR 46.101(2)].

The following documents have been acknowledged for use in this study and are available in the BRAAN system:

Surveys, Questionnaires, Interviews

Attachments

Flood disaster questions.doc

Miscellaneous Attachments

Attachments 
APPENDIX B

Participant Informational Letter 


\section{WestVirginiaUniversity}

School of Nursing

November 3, 2010

Dear Invited Participant in a Research Study,

My name is Margaret Rateau and I am a registered nurse currently working toward a PhD in nursing at West Virginia University. As part of the dissertation for my PhD I am conducting a research study that involves the collection of stories from those who have experienced catastrophic losses to home and property caused by the massive flooding from Hurricane Ivan in Sept. 2004. These stories are important in the long-term recovery for those who have experienced loss from the flood.

I am asking for your help in this endeavor. If you were affected by the massive flooding from Hurricane Ivan in Sept. 2004 , are 18 years of age or older, and you or others were displaced from the household for 12 hours or more; please contact me. I would very much like to hear your story. A small incentive will be provided to you if agree to share your story with me. There will be no penalty if choose not to participate and if you agree to participate in this research study you are not obligated to answer all questions that may be asked of you and you may withdraw from the study at any time. The interview will be tape recorded and all information will be kept confidential.

The primary investigator (PI) for this research study is Dr. Mary Jane Smith PhD, RN- Professor and Associate Dean for Graduate Academic Affairs. Dr. Smith's contact information follows. Dr. Mary Jane Smith, WVU School of Nursing, P.O. Box 9640, Morgantown, WV 26506-9600 Telephone: (304) 293-4298; E-mail: mjsmith@hsc.wvu.edu

Here is my contact information. Please contact me if you wish to participate in this research study.

Margaret Rateau, MSN, RN

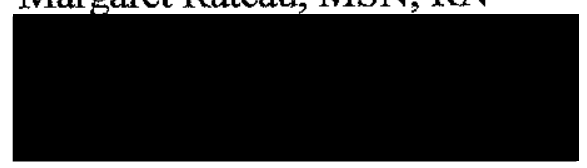

Thank you for your assistance in this study. Please feel free to contact me for further information or with questions. West Virginia University's Institutional Review Board (IRB) has acknowledgement of this study on file. 